\title{
Titanium Nitride/Carbon Coatings on Graphite Fibers
}

\author{
Yin Liu," David R. Treadw ell," Mike R. Kannisto, Brian L. Mueller, and Richard M. Laine* \\ Department of Materials Science and Engineering and Department of Chemistry, University of Michigan, \\ Ann Arbor, Michigan 48109-2136
}

Titanium nitride (TiN) coatings were applied to graphitefiber tows by dip coating desized $\left(900^{\circ} \mathrm{C}\right.$ in nitrogen) fibers in hexane solutions containing 0.5 , 1 , or 2 equivalent wt $\%$ TiN as the precursor, $-\left[\mathrm{Ti}\left(\mathrm{NMe}_{2}\right)_{x}\left(\mu-\mathrm{NCHMe}_{2}\right)_{4-2 x}\right]_{n}-$. The precursor was characterized by thermogravimetric analysis (TGA), chemical analysis, and nuclear magnetic resonance. Bulk samples of precursor were heated to selected temperatures in argon. Based on microstructural and chemical analyses, two pyrolysis temperatures $-900^{\circ}$ and $1200^{\circ} \mathrm{C}-$ were selected for more-detailed studies predicated on fiber oxidation-resistance behavior. At $900^{\circ} \mathrm{C}$, the bulk material exhibited a powder X-ray diffractometry (XRD) pattern consistent with microcrystalline TiN, although some free carbon remained. XRD analysis of the samples pyrolyzed to $1200^{\circ} \mathrm{C}$ indicated a higher degree of crystallinity and some carbon incorporation in the TiN lattice; e.g., a TiCN solid solution forms, as supported by chemical and TGA analyses. Fibers coated with precursor were heated at a rate of $10^{\circ} \mathrm{C} / \mathrm{min}$ in argon to selected temperatures, followed by a hold for $1 \mathrm{~h}$, and the resulting coatings were characterized by scanning electron microscopy, X-ray photoemission spectroscopy, and oxidation resistance at $700^{\circ} \mathrm{C}$ for $2 \mathrm{~h}$ in air. Coated fibers pyrolyzed to $900^{\circ}$ and $1200^{\circ} \mathrm{C}$ were studied in detail. Fibers heat treated at $900^{\circ} \mathrm{C}$ exhibited better oxidation resistance than fibers pretreated at $1200^{\circ} \mathrm{C}$, as determined by mass loss. Uncoated fiber tows fully oxidized after $80 \mathrm{~min}$. The oxidation-resistance studies on fiber tows pretreated at $900^{\circ} \mathrm{C}$ and coated with $0.5,1$, and 2 equivalent wt \% TiN indicated that the sample with a coating of $1 \mathrm{wt} \%$, with thicknesses of $0.1-0.2 \mu \mathrm{m}$, was the most stable. The coatings of 0.5 equivalent $\mathrm{wt} \% \mathrm{TiN}$ were irregular, whereas the coatings of 2 equivalent wt $\%$ TiN exhibited processrelated cracking, leading to poor oxidation resistance.

\section{Introduction}

$\mathrm{T}$ HE performance of fiber-reinforced (polymer-, metal-, and ceramic-matrix composites (PMCs, MMCs, and CMCs, respectively $)^{1,2}$ depends greatly on the interaction between the composite components at mutual interfaces. ${ }^{3-5}$ Fiber coatings are commonly used to modify interfacial interactions to optimize a variety of properties. ${ }^{5-10}$ In actual use, they are expected to be multifunctional; i.e., they can enhance composite mechanical properties and protect fibers from chemical reaction with the environment.

Graphite fibers, which offer high specific strengths at relatively low cost, are widely used to reinforce all types of composites. $^{6}$ Unfortunately, they oxidize readily at temperatures of $>500^{\circ} \mathrm{C}$, which restricts their use as reinforcing materials for MMCs and CMCs and increases the difficulty of composite fabrication. ${ }^{7}$ They also can react with matrix materials in

C. G. Pantano-contributing editor

Manuscript No. 192035. Received February 9, 1996; approved September 16, 1996. Supported by the U.S. Office of Naval Research.

"Member, American Ceramic Society.
MMCs to form metal carbides (e.g., $\mathrm{Al}_{4} \mathrm{C}_{3}$ in aluminum matrices), which damages fiber integrity, the matrix, and the interface. $^{8}$ The development of diffusion barriers that eliminate chemical reactions between graphite fibers and the matrix or the processing environment, while also providing appropriate interfacial mechanical properties, could resolve these problems.

To date, coating materials including $\mathrm{TiC}, \mathrm{SiC}, \mathrm{SiO}_{x} \mathrm{C}_{y}, \mathrm{BN}$, $\mathrm{B}_{4} \mathrm{C}, \mathrm{Al}_{2} \mathrm{O}_{3}$, and $\mathrm{MgO}$ have been explored as a means of controlling interfacial properties and passivating graphite-fiber surfaces. ${ }^{4,5,9,10}$ The wide variety of coating materials studied and required in MMC and CMC fabrication is predicated on the widely differing adhesive properties and chemical reactivities of the composite matrix materials used. Many of these coatings are readily applied via chemical or physical vapor deposition (CVD or PVD, respectively); however, both approaches are equipment and energy intensive. Consequently, we and others are exploring the use of dip coating fiber tows with preceramic polymer solutions, followed by firing, as a low-cost, alternative approach to high-quality coatings. To date, we have examined the fabrication of $\mathrm{SiO}_{x} \mathrm{C}_{y}$ and mullite coatings on graphite fibers. ${ }^{4,5}$ Here, we describe efforts to develop precursor-derived non-oxide coatings, with the initial focus on TiN.

TiN coatings are quite hard (22-32 GPa), which makes them useful in cutting-tool applications. ${ }^{11}$ TiN also bonds strongly to many metals - e.g., aluminum alloys and steels-and, thus, may be a good interfacial material in MMCs. ${ }^{12} \mathrm{TiN}$ is isomorphous with $\mathrm{TiC}$, which has already found use as a carbonfiber coating. ${ }^{13}$ TiN exhibits high-temperature stability, with a melting point of $2930^{\circ} \mathrm{C}$ and good chemical stability, ${ }^{14}$ and is used for diffusion barriers in electronics and superalloy applications. ${ }^{15-17}$ In addition, a polymeric precursor to $\mathrm{TiN}$ is readily available (see below). Unfortunately, TiN is susceptible to oxidation, ${ }^{14}$ although the oxidation products $\mathrm{TiO}_{x} \mathrm{~N}_{y}$ and $\mathrm{TiO}_{2}$ also are potentially useful coating materials. All of these suggest that TiN coatings may be of benefit in passivating carbon fibers and providing good-to-excellent interfacial properties.

TiN coatings are commonly produced via PVD and CVD methods. ${ }^{11,18} \mathrm{Ti}\left(\mathrm{NMe}_{2}\right)_{4}$ (where $\mathrm{Me}$ is a methyl group) is frequently used as a CVD precursor and provides high-quality TiN coatings. ${ }^{14} \mathrm{TiCl}_{4}$ also has been used as a CVD precursor to produce $\mathrm{TiC}$ coatings on graphite fibers and TiN coatings on boron fibers. ${ }^{9,13}$ Although the resulting coatings perform well, as noted above, CVD is equipment and energy intensive and, therefore, expensive. Moreover, both methods are inconvenient for processing large quantitites of fiber tows.

In principle, simply dipping continuous-fiber tows in a precursor solution and then heating the fiber tows to decompose the precursor coating to produce a uniform, defect-free ceramic coating appears simple and straightforward. In practice, two difficulties are encountered: (i) removing the organic ligands so that carbon contamination is avoided is not always easy, and (ii) obtaining good wetting such that uniform coatings of desired thickness are obtained is often hard. ${ }^{19}$ The work reported here targets the use of soluble titanium amide precursors for dip coating graphite-fiber tows to produce uniform and defect-free TiN coatings following pyrolysis, with controlled coating properties, especially improved oxidation resistance. 


\section{Experimental Procedure}

Thornel P-55 carbon fibers (Amoco, Chicago, IL) were used for dip coating. The as-received fiber properties include a typical diameter of $\sim 10 \mu \mathrm{m}$ (with sizing), a specific gravity of $2.0 \mathrm{~g} / \mathrm{cm}^{3}$, a tensile modulus of $380 \mathrm{GPa}$, a tensile strength of $1.90 \mathrm{GPa}$, a strain to failure of $0.5 \%$, and a coefficient of thermal expansion of $-0.9 \times 10^{-6}{ }^{\circ} \mathrm{C}^{-1}\left(0^{\circ}-100^{\circ} \mathrm{C}\right.$, longitudinal). Methyllithium $\left(\mathrm{CH}_{3} \mathrm{Li}\right)$, in diethyl ether, as the lithium bromide complex (1.5M solution), and dimethylamine, $\mathrm{Me}_{2} \mathrm{NH}$, anhydrous $(99+\%)$, were purchased from Aldrich Chemical Co. (Milwaukee, WI). Titanium tetrachloride $\left(\mathrm{TiCl}_{4}, 99 \%\right)$ was purchased from Alfa Co. (Ward Hill, MA). Isopropylamine, $\mathrm{Me}_{2} \mathrm{CHNH}_{2}(99 \%)$, was purchased from Pfaltz and Bauer (Waterbury, CT) and dried over $\mathrm{CaH}_{2}$ before use. Hexanes $(85 \%$ $n$-hexane) and toluene (Mallinckrodt, St. Louis, MO) were distilled from the appropriate drying agents under $\mathrm{N}_{2}$ and stored under $\mathrm{N}_{2}$ prior to use. All manipulations of air- or watersensitive materials were conducted in argon or $\mathrm{N}_{2}$ atmospheres using standard schlenk or glove-box techniques.

\section{(1) Synthesis and Characterization of the TiN Polymer Precursor}

(A) TiN Precursor: $\mathrm{Ti}\left(\mathrm{NMe}_{2}\right)_{4}(8.9 \mathrm{~g})$, synthesized by the method of Bradley, ${ }^{20}$ was dissolved in $20 \mathrm{~mL}$ of toluene in a $100 \mathrm{~mL}$ schlenk flask fitted with an efficient reflux condenser and a stir bar. The flask was placed in an oil bath at $60^{\circ} \mathrm{C}$ $\left( \pm 2^{\circ} \mathrm{C}\right)$. Isopropylamine $(4.24 \mathrm{~mL})(49.8 \mathrm{mmol}$, density of $0.694 \mathrm{~g} / \mathrm{mL}$ ), was added (ratio of $1.25 \mathrm{~mol}: 1 \mathrm{~mol}$ titanium). Small bubbles immediately emerged from the solution, and the solution color changed from yellow to dark orange. To facilitate removal of dimethylamine, a slow stream of argon was admitted through the flask side arm and removed at the top of the condenser. After $6 \mathrm{~h}$, no further bubbling was observed, and the reaction was assumed to be complete. On the removal of solvent, $14.6 \mathrm{~g}$ of precursor were recovered. The yield of TiN precursor, based on the proposed formula $\left.\mathrm{Ti}\left[\mathrm{NCH}_{3}\right)_{2}\right]_{1.25}-$ $\left[\mathrm{N}\left(\mathrm{CHCH}_{3}\right)_{2}\right]_{1.25}$, was $80 \%$ of theory.

(B) Nuclear Magnetic Resonance: Nuclear magnetic resonance (NMR) spectra were obtained on a spectrometer (Model Aspect 3000, AM-360 NMR, Bruker Co., Germany) operated at $360\left({ }^{1} \mathrm{H}\right)$ or $90.6\left({ }^{13} \mathrm{C}\right) \mathrm{MHz}$ using $30^{\circ}$ pulse widths and relaxation delays of $1.0\left({ }^{1} \mathrm{H}\right)$ and $0.5\left({ }^{13} \mathrm{C}\right) \mathrm{s}$. TiN precursor samples $(0.2 \mathrm{~mL})$ were dried under vacuum, then dissolved in $0.5 \mathrm{~mL}$ of $\mathrm{C}_{6} \mathrm{D}_{6}$ (Cambridge Isotope Labs, Cambridge, MA) under $\operatorname{argon}(\mathrm{D}$ is deuterium), and then transferred to $5 \mathrm{~mm}$ NMR tubes. All chemical shifts are reported as parts per million (ppm) downfield of tetramethylsilane (TMS) (Aldrich).

(C) Thermal Analytical Techniques: Thermogravimetric analysis (TGA) studies were performed using a thermal analysis instrument (Model Hi-Res TGA 2950, TA Instruments, New Castle, DE). The sample and a platinum sample pan were weighed in an argon glove box and then transported out and loaded in the TGA instrument in an $\mathrm{N}_{2}$ environment. The TGA was ramped at $10^{\circ} \mathrm{C} / \mathrm{min}$ to $1000^{\circ} \mathrm{C}$ at the "High-Res 4" setting, with a $40 \mathrm{~cm}^{3} / \mathrm{min} \mathrm{N}_{2}$ balance flow and a $60 \mathrm{~cm}^{3} / \mathrm{min}$ air purge flow. The ceramic yield $\left(\mathrm{TiO}_{2}\right)$ for the precursor was $22.02 \%$ at $1000^{\circ} \mathrm{C}$ in air, corresponding to a TiN yield of $17.06 \%$. The oxidation-resistance studies also were conducted by TGA, as discussed in the following section.

\section{(2) Pyrolyses and Characterization of the Bulk Precursor}

(A) Bulk Precursor Pyrolysis Studies: A typical experiment consisted of the following steps: (i) pumping a sample of precursor under dynamic vacuum for $3 \mathrm{~h}$ to remove traces of solvent and generate a viscous, red oil; (ii) transferring the sample to an argon glove box; (iii) placing 500 mg of precursor into an alumina boat; (iv) placing the boat into a quartz tube; (v) sealing the quartz tube with a ported glass cap for gas ingress and egress; and finally (vi) taking the tube out of the argon glove box and placing it in a tube furnace (Model No. 58114 , Lindberg, Watertown, WI) equipped with a programmable temperature controller (Model 818P, Eurotherm, Northing,
U.K.). Samples were then heated at a rate of $10^{\circ} \mathrm{C} / \mathrm{min}$ to temperatures in the $200^{\circ}-1200^{\circ} \mathrm{C}$ range in $200^{\circ} \mathrm{C}$ increments with a dwell time of $2 \mathrm{~h}$ at temperature, with argon flow passing through the quartz tube. The argon was prepurified by passing it through a heated column $\left(150^{\circ} \mathrm{C}\right)$ of copper oxide. Samples were then cooled to room temperature, and the boat was reweighed to profile the ceramic yield at each temperature.

(B) Chemical Analysis: The vacuum-dried sample and the pyrolyzed samples were submitted for CHN analysis (chemical analysis for elemental carbon, hydrogen, and nitrogen). CHN analysis was conducted using an elemental analyzer (Model 2400 CHN, Perkin-Elmer, Norwalk, CT). The combustion tube was maintained at $1000^{\circ} \mathrm{C}$ with oxygen as the combustion gas, whereas the reduction tube was maintained at $640^{\circ} \mathrm{C}$ using helium as the carrier gas. The systematic error in measurements was $\pm 0.4 \mathrm{wt} \%$.

(C) XRD Studies: Powder X-ray diffractometry (XRD) patterns were taken using a rotating anode goniometer (Rigaku Denki Co. Ltd., Tokyo, Japan). Pyrolyzed samples were ground in air using an alumina mortar and pestle. Then, the ground samples (40-80 mg) were loaded in a sample holder (glass plates) for data collection. The working voltage and current were $40 \mathrm{kV}$ and $100 \mathrm{~mA}$, respectively. $\mathrm{CuK \alpha}(\lambda=1.54 \mathrm{~A})$ radiation with a nickel filter was used. Scans were continuous from $5^{\circ}-90^{\circ} 2 \theta$ with a step scan of $10^{\circ} 2 \theta / \mathrm{min}$ and increments of $0.05^{\circ} 2 \theta$. The peak positions and the relative intensities of the pyrolyzed products were characterized by comparison with standard International Centre for Diffraction Data (ICDD, Newtowne Square, PA) files.

\section{(3) Fiber-Coating Studies}

(A) Coating Precursor Solutions: Precursor solutions of $0.5,1$, and 2 equivalent wt $\% \mathrm{TiN}$ (200 g each) were made for fiber-coating studies. For example, a $200 \mathrm{~g}$ solution of $2 \mathrm{wt} \%$ TiN was made by mixing $177 \mathrm{~g}$ of hexane and $23.4 \mathrm{~g}$ of TiN precursor (TiN yield of $17.1 \mathrm{wt} \%$ ), prepared as described above, together in a glass container inside an argon dry box. The glass containers were predried at $150^{\circ} \mathrm{C}$ for $24 \mathrm{~h}$ in air and transported while hot into the argon dry-box vacuum chamber.

(B) Fiber-Coating Procedures and Pyrolysis: Prior to coating, the sizing on the Thornel P-55 carbon fibers was removed as follows. Tows of carbon fibers, $60-80 \mathrm{~cm}$ in length, were wrapped lengthwise on a $20 \mathrm{~cm} \times 5 \mathrm{~cm} \times 0.6 \mathrm{~cm}$ graphite rack and placed inside a ported quartz tube. The quartz tube was placed in a Lindberg tube furnace and heated (in flowing argon) at $10^{\circ} \mathrm{C} / \mathrm{min}$ to $900^{\circ} \mathrm{C}$ and held for $1 \mathrm{~h}$ to decompose the polymer sizing. The system was then allowed to furnace cool. Fibers were coated as follows.

For oxidation-resistance studies, the desized carbon-fiber tows were cut to lengths of 3-5 mm, placed into an argon glove box, and dipped in $0.5,1$, or 2 equivalent wt $\%$ TiN precursor solutions. After soaking for $2 \mathrm{~min}$, the fibers were removed and allowed to dry for $15 \mathrm{~min}$ in the argon environment. The fibers were then placed in an alumina boat and loaded in the ported quartz tube again and heated $\left(10^{\circ} \mathrm{C} / \mathrm{min} / \mathrm{Ar}\right)$ to selected temperatures $\left(100 \mathrm{~cm}^{3} / \mathrm{min}\right)$ and held at temperature for $1 \mathrm{~h}$.

Longer fiber tows also were coated with the 1 or 2 equivalent wt\% TiN solution. A rack containing the desized tows was dipped into the 1 or 2 equivalent wt $\%$ TiN solution, allowed to stand for $2 \mathrm{~min}$, removed, and allowed to dry for $15 \mathrm{~min}$ in an argon environment. The dried fibers were heat treated in a manner identical to the cut fiber tows.

(C) Oxidation-Resistance Studies: Coatings were tested using TGA. Approximately $5 \mathrm{mg}$ of fiber tow (3-5 $\mathrm{mm}$ in length, coated after cutting) were loaded in a platinum pan, heated at $50^{\circ} \mathrm{C} / \mathrm{min}$ to $700^{\circ} \mathrm{C}$, and held for $2 \mathrm{~h}$ in air $\left(40 \mathrm{~cm}^{3} / \mathrm{min}\right.$ $\mathrm{N}_{2}$ balance and $60 \mathrm{~cm}^{3} / \mathrm{min}$ air purge flow).

(D) Scanning Electron Microscopy: The surface appearances of desized and coated carbon fibers were examined using a scanning electron microscopy (SEM) microscope (Model S800, Hitachi, Tokyo, Japan) operating at $5 \mathrm{keV}$. SEM samples were prepared by mounting carbon-fiber tows $(3-5 \mathrm{~mm}$ in length) on an aluminum stub using carbon paste. 
(E) X-ray Photoelectron Spectroscopy: X-ray photoemission spectroscopy (XPS) spectra for bulk pyrolyzed powders and coated fibers were collected using an X-ray photoelectron spectrometer (Model 5400, PHI, Industry, CA). The powder XPS data were used as a reference for the fiber-coating analyses. A Mg X-ray source was operated at $300 \mathrm{~W}$ and $15 \mathrm{kV}$. The operating pressure was kept at $\sim 1.3 \times 10^{-7} \mathrm{~Pa}\left(\sim 10^{-9}\right.$ torr $)$ to minimize the signal from air. A small-area omni focus of $1 \mathrm{~mm}^{2}$ was selected for sample analysis, and a neutralizer was used to prevent charge buildup.

Survey and multiplex analyses were conducted for each sample. Surveys were conducted over the $0-1000 \mathrm{eV}$ energy range with an acquisition time of $5 \mathrm{~min}$. The survey data provided basic information on peak positions for the elements found in the bulk powder and coating surfaces. Based on the survey information, multiplex analysis was performed for the interested energy ranges (or interested elements). The multiplex function gave a relatively accurate shape and position for the desired elemental peaks, from which the types of atomic bonding were evaluated, and permitted quantification of the surface compositions. Data were collected until the peaks of interest were visibly smooth (typically $1 \mathrm{~h}$ ).

For all sample surfaces, the original surface was analyzed first, and then the surface following ion milling was analyzed. Surfaces were cleaned by argon-ion milling for $>7 \mathrm{~min}$ for the powders and $>2.5 \mathrm{~min}$ for the fibers, with a beam voltage of $3 \mathrm{kV}$. Milling rates were $\sim 10 \mathrm{~A} / \mathrm{min}$.

\section{Results and Discussion}

\section{(1) Precursor Synthesis and Characterization}

The first goal in these studies was to develop an easily synthesized, rheologically useful, polymer precursor that transforms to dense, phase-pure $\mathrm{TiN}$ on pyrolysis. One other criterion requires that the precursor wet the substrate effectively to produce high-quality coatings. Based on previous efforts to synthesize non-oxide polymer precursors, ${ }^{21} \mathrm{Ti}\left(\mathrm{NMe}_{2}\right)_{4}$ was selected as the starting point for the synthesis of a processable TiN precursor. ${ }^{14,19,20}$

Because $\mathrm{Ti}\left(\mathrm{NMe}_{2}\right)_{4}$ is too volatile for fiber-coating purposes $^{20,22,23}$ and because methyl groups are likely to promote the formation of $\mathrm{TiC}^{24,25}$ a nonvolatile, soluble precursor with few methylamide moieties was sought. ${ }^{26}$ Precursor solutions are potentially ideal for controlling coating thickness, because this can be done by simple adjustment of the precursor concentration, provided that good wetting can be obtained.

The TiN polymer precursor used in these studies was prepared by reacting $\mathrm{Ti}\left(\mathrm{NMe}_{2}\right)_{4}$ with 1.25 equiv of isopropylamine. The choice of 1.25 equiv was predicated on the need for a viscous polymer that coats well. Efforts to use $>1.25$ equiv resulted in highly crosslinked, intractable solids. The addition of isopropylamine, followed by heating, transformed yellow $\mathrm{Ti}\left(\mathrm{NMe}_{2}\right)_{4}$ hexane solutions to dark orange as dimethylamine was eliminated and the polymer formed:

$$
\begin{aligned}
\operatorname{Ti}\left[\mathrm{N}\left(\mathrm{CH}_{3}\right)_{2}\right]_{4}+ & 1.25\left(\mathrm{CH}_{3}\right)_{2} \mathrm{CHNH}_{2} \stackrel{60^{\circ} \mathrm{C}}{\longrightarrow} \\
& \text { Polymeric precursor }+2.5\left(\mathrm{CH}_{3}\right)_{2} \mathrm{NH} \uparrow
\end{aligned}
$$

If reaction (1) proceeds as anticipated, the resulting polymer should be partially crosslinked with a structure similar to<smiles></smiles>

and with an empirical formula of $\mathrm{C}_{6.75} \mathrm{~N}_{2.75} \mathrm{H}_{17.75}$ Ti. Dimeric (e.g. $\left.\left[\left(\mathrm{CH}_{3}\right)_{2} \mathrm{~N}\right]_{2} \mathrm{Ti}(\mathrm{NR})_{2} \mathrm{Ti}\left[\left(\mathrm{CH}_{3}\right)_{2} \mathrm{~N}\right]_{2}\right)$ and oligomeric species are known to form. ${ }^{20}$ We believe that the product obtained here is polymeric, based on the initial reaction stoichiometry, NMR and $\mathrm{CHN}$ analyses, and the TGA ceramic yield at $1000^{\circ} \mathrm{C}$ (see below).

(A) NMR Studies: NMR of the ${ }^{13} \mathrm{C}$ solution was used to establish a general solution structure. The ${ }^{13} \mathrm{C}$ values for $\mathrm{Me}_{2} \mathrm{NH}, i \mathrm{PrNH}_{2}$, and $\mathrm{Ti}\left(\mathrm{N}\left(\mathrm{CH}_{3}\right)_{2}\right)_{4}$, listed in Table I, provide resonances that support the proposed general molecular structure. For example, the carbon in free $\mathrm{Me}_{2} \mathrm{NH}$ shifts from $36.8 \delta$ to $44.4 \delta(\Delta=7.6 \delta)$ when bound as an amido group in $\mathrm{Ti}\left(\mathrm{NMe}_{2}\right)_{4}$. The secondary carbon peak position of $i \mathrm{PrNH}_{2}$ shifts from $43.3 \delta$ in the free amine to $61.3 \delta(\Delta=18.0 \delta)$ in the precursor complex. This much-larger shift likely results from an isopropylimido group bridging two titanium atoms rather than an amido complex. ${ }^{20 c}$ Proton NMR resonances (Table II) for the $\mathrm{Me}_{2} \mathrm{~N}$ and $i \mathrm{PrN}$ ligands shift as expected for terminal amides and bridging imides, respectively. Four distinct peaks are observed, suggesting a distribution of species, as expected for a partially crosslinked polymer. The dimer, if present, forms coincident with a number of oligomeric titanium species.

(B) CHN Analysis: Chemical analysis of the vacuumdried precursor gave the following values (in wt \%): carbon, 43.1; hydrogen, 8.7; and nitrogen, 19.2 ( $\pm 0.4 \mathrm{wt} \%)$. Values calculated for $\mathrm{C}_{6.75} \mathrm{~N}_{2.75} \mathrm{H}_{17.75} \mathrm{Ti}$, corresponding to $\{\mathrm{Ti}[\mathrm{NCH}-$ $\left.\left.\left(\mathrm{CH}_{3}\right)_{2}\right]_{1.25}\left[\mathrm{~N}\left(\mathrm{CH}_{3}\right)_{2}\right]_{1.5}\right\}$, are as follows (in wt\%): carbon, 43.8; hydrogen, 9.5; nitrogen, 20.8; and titanium, 25.9. These calculations assume a high polymer and do not include contributions from any remaining $\mathrm{Me}_{2} \mathrm{~N}-$ end groups. These values are relatively similar and, together with the NMR data, suggest that the proposed structure is reasonably accurate, as also supported by the TGA results below. The moisture sensitivity of the precursor precludes gel-permeation chromatographic molecularweight analysis.

(C) TGA Analysis: The TGA ceramic yield at $1000^{\circ} \mathrm{C}$ (at a rate of $10^{\circ} \mathrm{C} / \mathrm{min}$ in air) for the vacuum-dried precursor is $43.23 \%$. The off-white powder has been shown by XRD to be $\mathrm{TiO}_{2}$. The theoretical $\mathrm{TiO}_{2}$ yield, based on the proposed empirical formula, is $43.09 \%$, which is within the error limits of the analysis method and again supports the proposed precursor structure.

\section{(2) Bulk Material Studies}

The TiN precursor-to-ceramic transformation process, as a function of the pyrolysis temperature, was followed by massloss behavior and CHN, XPS, and XRD analyses to identify the various chemical and microstructural changes that occur. These

\begin{tabular}{|c|c|c|c|}
\hline \multirow[b]{2}{*}{ Chemical compound } & \multicolumn{3}{|c|}{${ }^{13} \mathrm{C}$ chemical shift ${ }^{\dagger}(\delta)$} \\
\hline & $\mathrm{C}^{1}$ & $\mathrm{C}^{2}$ & $\mathrm{C}^{3}$ \\
\hline $\begin{array}{l}\mathrm{HN}\left(\mathrm{C}^{3} \mathrm{H}_{3}\right)_{2} \\
\mathrm{H}_{2} \mathrm{NC}^{1} \mathrm{H}\left(\mathrm{C}^{2} \mathrm{H}_{3}\right)_{2}\end{array}$ & 26.69 & 43.27 & 36.79 \\
\hline $\operatorname{Ti}\left(\mathrm{N}\left(\mathrm{C}^{3} \mathrm{H}_{3}\right)_{2}\right)_{4}$ & 20.07 & 40.21 & 44.38 \\
\hline$\Delta \delta$ of $\mathrm{HN}\left(\mathrm{C}^{3} \mathrm{H}_{3}\right)_{2}$ on complexation with titanium & & & 7.60 \\
\hline TiN polymer precursor & 29.92 & 61.27 & $47.13,47.65,48.11$ \\
\hline$\Delta \delta$ of $\mathrm{HN}\left(\mathrm{C}^{3} \mathrm{H}_{3}\right)_{2}$ and $\mathrm{H}_{2} \mathrm{NC}^{1} \mathrm{H}\left(\mathrm{C}^{2} \mathrm{H}_{3}\right)_{2}$ on complexation with titanium & 3.23 & 18.00 & $10.34,10.86,11.32$ \\
\hline
\end{tabular}

Table I. ${ }^{13} \mathrm{C}$ NMR Peak Positions for TiN Precursor

${ }^{\top}$ Spectra taken in benzene- $\mathrm{d}_{6}$, using tetramethylsilane (TMS) as an internal standard. $\mathrm{C}^{1}$ is the primary carbon in isopropylamine/isopropylimide, $\mathrm{C}^{2}$ is the secondary carbon in isopropylamine/isopropylimide, and $\mathrm{C}^{3}$ is the carbon is dimethylamine/dimethylamide. 
Table II. $\quad{ }^{1} \mathrm{H}$ Peak Positions for TiN Precursor

\begin{tabular}{|c|c|c|c|}
\hline \multirow[b]{2}{*}{ Chemical compound } & \multicolumn{3}{|c|}{${ }^{1} \mathrm{H}$ chemical shift' $(\delta)$} \\
\hline & $\mathrm{H}^{1}$ & $\mathrm{H}^{2}$ & $\mathrm{H}^{3}$ \\
\hline $\mathrm{HN}\left(\mathrm{CH}_{3}^{3}\right)_{2}$ & & & 2.18 singlet \\
\hline $\begin{array}{l}\mathrm{H}_{2} \mathrm{NCH}^{1}\left(\mathrm{CH}_{3}^{2}\right)_{2} \\
\mathrm{Ti}\left[\mathrm{N}\left(\mathrm{CH}_{3}^{3}\right)_{2}\right]_{4}\end{array}$ & 2.87 septet $^{\ddagger}$ & 0.92 doublet $^{\ddagger}$ & 3.10 singlet \\
\hline $\begin{array}{l}\Delta \delta \text { of } \mathrm{HN}\left(\mathrm{CH}_{3}^{3}\right)_{2} \text { on } \\
\text { complexation with titanium }\end{array}$ & & & 0.93 \\
\hline $\begin{array}{l}\text { TiN polymer precursor } \\
\Delta \delta \text { of } \mathrm{HN}\left(\mathrm{CH}_{3}^{3}\right)_{2} \text { and } \\
\end{array}$ & $3.82,4.36,4.53$ septet $^{\ddagger}$ & 1.21 doublet, ${ }^{\ddagger} 1.41,1.47,1.52$ & 3.12 singlet, $3.18,3.20,3.26$ \\
\hline complexation with titanium & $0.94,1.49,1.66$ & $0.29,0.49,0.55,0.60$ & $0.94,1.01,1.02,1.09$ \\
\hline
\end{tabular}

${ }^{7} \mathrm{H}^{1}$ is the primary hydrogen in isopropylamine/isopropylimide, $\mathrm{H}^{2}$ is the secondary hydrogen in isopropylamine/isopropylimide, and $\mathrm{H}^{3}$ is the hydrogen in dimethylamine/ dimethylamide. ${ }^{*}$ At $J_{\mathrm{HH}} 6.3 \mathrm{~Hz}$.

studies were conducted to establish guidelines for processing and characterizing precursor-derived TiN coatings on graphite fibers.

(A) Pyrolysis Studies: We previously reported that the isobutyrate ligand $\left(i \mathrm{PrCO}_{2}\right)$ can be used as a general means of forming processable metal-oxide precursors. ${ }^{27}$ These results prompted our efforts to use isopropylamine to form a processable TiN precursor. An additional motivation for choosing a secondary amine was the fact that the thermolysis of amine ligands with $\beta$-hydrogens frequently leads to direct cleavage of the $\mathrm{C}-\mathrm{N}$ bond ${ }^{28}$ rather than the metal- $\mathrm{N}$ bond, per reaction (2):

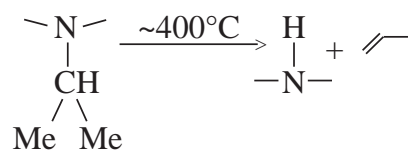

Isopropyl rather than $n$-propyl groups were chosen to promote $\mathrm{C}-\mathrm{N}$ bond cleavage, because the isopropyl moiety has six, rather than two, $\beta$-hydrogens and cleavage is more favorable if secondary carbon radicals form. ${ }^{20 \mathrm{c}}$ The isopropyl groups would then most likely evolve as propene (reaction (2)), ${ }^{24}$ generating hydrogenated $\mathrm{TiN}\left(\mathrm{Ti}_{x} \mathrm{~N}_{y} \mathrm{H}_{z}\right)$ first and then $\mathrm{TiN}$ on continued heating, because the residual hydrogen is lost as $\mathrm{H}_{2}$ or $\mathrm{CH}_{4}$, if any methyl groups remain. If pure TiN forms, then the theoretical ceramic yield would be $33.39 \%$, based on an initial composition of $\mathrm{C}_{6.75} \mathrm{~N}_{2.75} \mathrm{H}_{17.75} \mathrm{Ti}$.

The actual weight changes that occur when the dry precursor is pyrolyzed in $200^{\circ} \mathrm{C}$ increments from $200^{\circ} \mathrm{C}$ to $1200^{\circ} \mathrm{C}$ are shown in Fig. 1. On heating to $400^{\circ} \mathrm{C}$, the polymerlike precursor transforms to a brittle material, suggesting extensive crosslinking and/or mineralization. The $50 \%$ mass loss at $400^{\circ} \mathrm{C}$ likely results from $\mathrm{C}-\mathrm{N}$ bond cleavage, per reaction (2). On further heating to $800^{\circ} \mathrm{C}$, an additional mass loss of $7 \%$ is observed,

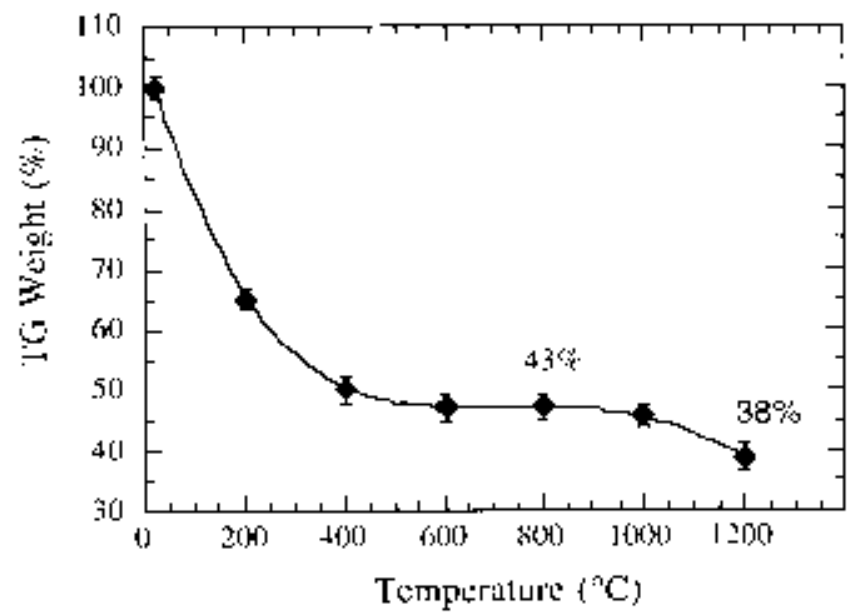

Fig. 1. Mass changes for TiN precursor pyrolyzed to selected temperatures for $2 \mathrm{~h}$ in argon. most of which appears to be nitrogen (see below). The mass losses at temperatures of $>800^{\circ} \mathrm{C}$ also may result from the loss of nitrogen.

Chemical analysis indicates that the pyrolysis product is never pure TiN. The data in Fig. 1 show a $43 \%$ ceramic yield at $900^{\circ} \mathrm{C}$, the pyrolysis temperature used for processing coated fibers. This value is $23 \mathrm{wt} \%$ higher than theory for pure TiN. In previous work, we observed that $\mathrm{Mo}_{2}\left(\mathrm{NMe}_{2}\right)_{6}$, on pyrolysis, converts to $\mathrm{Mo}_{2} \mathrm{C} ;{ }^{24}$ thus, the excess mass observed here is likely to be carbon that has been retained either as free carbon (graphitic or amorphous) or as the carbide, TiC.

In the samples pyrolyzed to $900^{\circ} \mathrm{C}$, the carbon appears to be present as free carbon, based on TGA experiments (at a rate of $10^{\circ} \mathrm{C} / \mathrm{min}$ in air to a temperature of $1000^{\circ} \mathrm{C}$ ) involving samples prepyrolyzed to $900^{\circ}$ or $1200^{\circ} \mathrm{C}$. The samples prepyrolyzed to $900^{\circ} \mathrm{C}$ show a mass loss of $5 \mathrm{wt} \%$. In contrast, pure TiN exhibits a $29 \%$ mass gain (also theory) when converted to $\mathrm{TiO}_{2}$ under similar TGA conditions. These differences in mass gain/loss are accounted for if free carbon is present in the pyrolyzed material, because it will convert to $\mathrm{CO}$ or $\mathrm{CO}_{2}$ on heating in air. From these mass-loss differences, the sample pyrolyzed to $900^{\circ} \mathrm{C}$ can be calculated to contain $25 \mathrm{wt} \%$ free carbon, which is similar to the values of $22 \mathrm{wt} \%$, obtained by chemical analysis (see Fig. 2 and Table III), and $23 \mathrm{wt} \%$, calculated from the Fig. 2 data, assuming the initial precursor composition is $\mathrm{C}_{6.75} \mathrm{~N}_{2.75} \mathrm{H}_{17.75} \mathrm{Ti}$ and the sample transforms to pure TiN plus excess carbon.

The samples pyrolyzed to $1200^{\circ} \mathrm{C}$ exhibit a mass gain of $5 \mathrm{wt} \%$ on heating in air. If the mass-loss difference of $24 \mathrm{wt} \%$ (vs the anticipated $29 \mathrm{wt} \%$ gain) is a consequence of free carbon, these data correspond to $19 \mathrm{wt} \%$ free carbon present, which is less than the value of $25 \mathrm{wt} \%$ obtained by chemical analysis (see Fig. 2 and Table III). The XRD data presented below suggest that, at $1200^{\circ} \mathrm{C}$, the remaining 5-6 wt $\%$ carbon is present as the carbide; i.e., TiCN has formed.

An additional argument for the presence of free carbon is that the alternative, based on the chemical analysis, would be the formation of mixtures of titanium carbide, titanium nitride, and carbon nitride. To date, true carbon nitride has not been synthesized. ${ }^{29-34}$ Thus, we believe that the possibility of a $\mathrm{C} / \mathrm{N}$ solid solution forming in the materials produced here is unlikely.

(B) Precursor Evolution as a Function of Pyrolysis Temperature (Chemistry): The chemical changes that occur as a function of pyrolysis temperature are discussed in terms of changes in elemental carbon, hydrogen, and nitrogen contents, as shown in Fig. 2. Hydrogen content changes in two stages. The major loss in hydrogen content occurs as the precursor transforms from a polymer to a ceramic char on heating to $550^{\circ} \mathrm{C}$, with coincident loss of organics, e.g., propene or methane. Similar decreases in carbon content occur for the same reason. By $550{ }^{\circ} \mathrm{C}$, the hydrogen content decreases to $<1 \mathrm{wt} \%$. Note that $1 \mathrm{wt} \%$ hydrogen is the equivalent of $1 \mathrm{~mol}$ of hydrogen. Therefore, considerable hydrogen still remains, most likely as $\mathrm{C}-\mathrm{H}$ and $\mathrm{N}-\mathrm{H}$ bonds in the carbonaceous char. Elimination of this remaining hydrogen must occur through thermolytic 


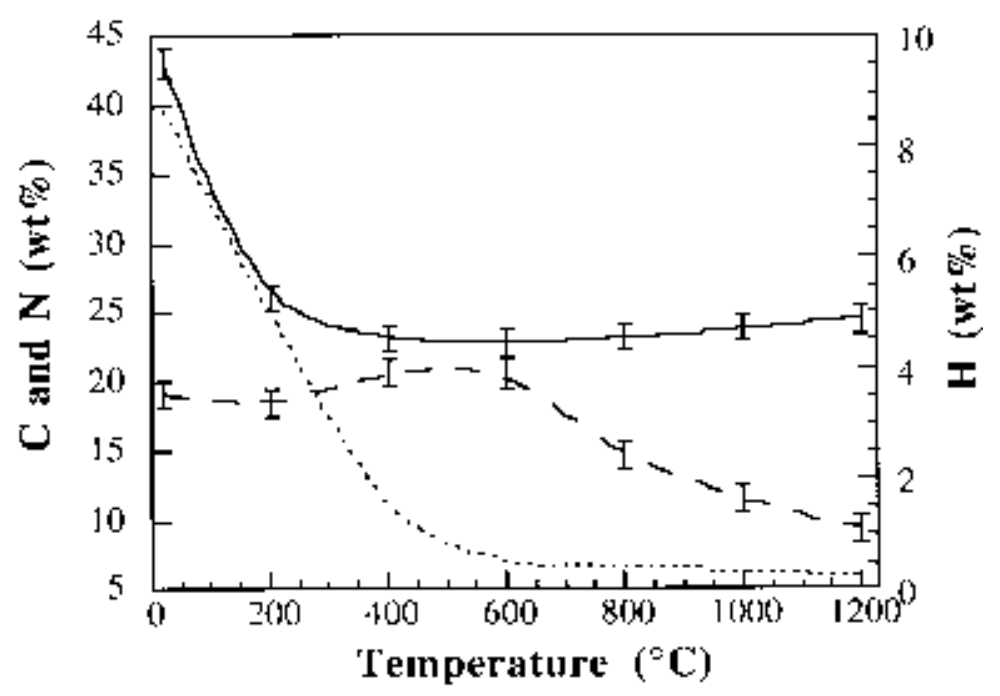

Fig. 2. CHN chemical analysis ((-) carbon, (- -) hydrogen, and (--) nitrogen) showing compositional changes on pyrolysis to selected temperatures for $2 \mathrm{~h}$ in argon.

processes that cause hydrogen atoms to diffuse through the material until sufficient numbers of hydrogen atoms collect on the same carbon or nitrogen atom so that $\mathrm{CH}_{4}$ or $\mathrm{NH}_{3}$ evolve. Alternately, $\mathrm{HCN}$ or other simple carbon-nitrogen compounds can evolve. ${ }^{34}$ Further loss of hydrogen is likely to be controlled by its diffusion rates in the char and will be slow until the highest pyrolysis temperatures are attained.

Carbon content also decreases on heating, until $550^{\circ} \mathrm{C}$, as organic ligands are expelled, as discussed above. The carbon content at this stage is $\sim 23 \mathrm{wt} \%$. On heating to higher temperatures, carbon content increases slightly, mostly as a consequence of nitrogen loss. In contrast to the carbon content, but in keeping with the expected generation of propene ${ }^{27}$ and methane, nitrogen content increases on heating to $550^{\circ} \mathrm{C}$, from $19 \mathrm{wt} \%$ to $21 \mathrm{wt} \%$ (Fig. 2). The nitrogen content then decreases to $10 \%$ at $1200^{\circ} \mathrm{C}$, most likely as a result of evolution of $\mathrm{NH}_{3}, \mathrm{HCN}$, or possibly $\mathrm{N}_{2}$. As found in the XPS studies, the Ti:N ratio at $900^{\circ} \mathrm{C}$ is $\sim 1: 1$. Thus, the considerable nitrogen loss on heating to $1200^{\circ} \mathrm{C}(\mathrm{Ti}: \mathrm{N}$ ratio $=2: 1)$ may coincide with the formation of $\mathrm{TiC}$ or $\mathrm{TiCN}$. Thus, fiber coatings pyrolyzed to $1200^{\circ} \mathrm{C}$ may convert to $\mathrm{TiC}$ or $\mathrm{TiCN}$ coatings. ${ }^{25,26}$ This provides the rationale for contrasting fiber coatings processed at $900^{\circ} \mathrm{C}$ with those processed at $1200^{\circ} \mathrm{C}$.

(C) XPS Data Analyses: Typically, XPS is used for the elemental analysis of surfaces. The XPS data for the pyrolyzed bulk precursor have been obtained to provide a reference for coating analyses (discussed in the following section). Table III presents XPS and chemical analyses for the precursor samples pyrolyzed to $900^{\circ}$ and $1200^{\circ} \mathrm{C}$.
Ion milling was used to clean the pyrolyzed precursor powder surfaces, to remove oxygen or other contaminants resulting from air exposure during XPS sample preparation. Ion milling removes $\sim 10 \mathrm{~A} / \mathrm{min}$ on a typical surface. However, because the XPS samples were pyrolyzed powders, rather than a simple plane surface, ion milling was prolonged and kept in a fixed direction to partially clean the powder surfaces. Some contribution from the original powder surfaces is likely to occur. Representative analyses of TiN and TiC surfaces from commercial powders are included in Tables III and IV for additional reference.

Because exposed surfaces adsorb oxygen during handling and sample preparation, the XPS data for the pyrolyzed bulk materials are not perfect. However, the data still suggest that the Ti:N ratio is $\sim 1: 1$ at $900^{\circ} \mathrm{C}$ but increases to $>2: 1$ for the sample pyrolyzed to $1200^{\circ} \mathrm{C}$, as mentioned above.

Figure 3 shows the Ti $2 p_{3 / 2}$ peaks for several samples. The Ti $2 p_{3 / 2}$ peak positions for commercial $\mathrm{TiC}$ and TiN powders are shown in Fig. 3(A). Both samples contain adsorbed oxygen (as $\mathrm{TiO}_{2}$ ) before ion milling, as indicated by the peak at $458.2 \mathrm{eV}$ for TiC and $457.8 \mathrm{eV}$ for TiN. ${ }^{35}$ After ion milling, although the $\mathrm{TiO}_{2} \mathrm{Ti} 2 p_{3 / 2}$ peak $(\sim 458 \mathrm{eV})$ still remains, the major Ti $2 p_{3 / 2}$ peaks display $\mathrm{TiC}$ and $\mathrm{TiN}$ binding energies, both of which are $454.2 \mathrm{eV}$.

The Ti $2 p_{3 / 2}$ peaks for the precursor pyrolyzed to $900^{\circ} \mathrm{C}$ are shown in Fig. 3(B). The bulk material, without ion milling, exhibits a $\mathrm{TiO}_{2}$ peak at $458 \mathrm{eV} .{ }^{35}$ After ion milling for $7 \mathrm{~min}$, the Ti $2 p_{3 / 2}$ peak shifts to a maximum at $454.2 \mathrm{eV}$. This suggests that the titanium that is present exists mainly as TiN $(454.8 \mathrm{eV}$,

Table III. XPS Data for Precursors Pyrolyzed to $900^{\circ}$ and $1200^{\circ} \mathrm{C}$ and for a Commercial TiN

\begin{tabular}{|c|c|c|c|c|c|c|}
\hline \multirow[b]{2}{*}{ Sample conditions } & \multicolumn{5}{|c|}{ Amount (at.\%) } & \multirow[b]{2}{*}{ Titanium:nitrogen ratio } \\
\hline & Carbon & Oxygen & Titanium & Nitrogen & Hydrogen & \\
\hline Pyrolyzed to $900^{\circ} \mathrm{C}$ & 37 & 41 & 12 & 10 & & 1.20 \\
\hline Pyrolyzed to $900^{\circ} \mathrm{C}$ & & & & & & \\
\hline ion milled for $16 \mathrm{~min}$ & 27 & 21 & 34 & 18 & & 1.89 \\
\hline Pyrolyzed to $1200^{\circ} \mathrm{C}$ & 61 & 23 & 11 & 5 & & 2.20 \\
\hline Pyrolyzed to $1200^{\circ} \mathrm{C}$, & & & & & & \\
\hline ion milled for $16 \mathrm{~min}$ & 46 & 23 & 24 & 7 & & 3.43 \\
\hline $\begin{array}{l}\mathrm{CHN} \text { chemical analyses for } \\
\text { sample pyrolyzed to } 900^{\circ} \mathrm{C}^{\dagger}\end{array}$ & $40.2(22.3)$ & & $28.9(64.2)$ & $20.1(13)$ & $10.8(0.5)$ & 1.44 \\
\hline $\begin{array}{l}\text { CHN chemical analyses for } \\
\text { sample pyrolyzed to } 1200^{\circ} \mathrm{C}^{\dagger}\end{array}$ & $47.1(24.6)$ & & $31.5(65.7)$ & $15.4(9.4)$ & $6.0(0.3)$ & 2.05 \\
\hline Commercial TiN & 24 & 34 & 24 & 18 & & 1.33 \\
\hline $\begin{array}{l}\text { Commercial TiN, ion milled for } \\
16 \text { min }\end{array}$ & & 14 & 50 & 36 & & 1.39 \\
\hline
\end{tabular}

"Values in parentheses are the corresponding wt $\%$ values $( \pm 0.4 \%)$. ${ }^{\star}$ Chemical analyses assume that carbon, hydrogen, nitrogen, and titanium are the only elements present in the precursor. 
Table IV. XPS Data for a Commercial TiC Powder

\begin{tabular}{|c|c|c|c|c|}
\hline \multirow[b]{2}{*}{ Sample } & \multicolumn{3}{|c|}{ Amount (at.\%) } & \multirow{2}{*}{$\begin{array}{c}\text { Titanium:carbon } \\
\text { ratio }\end{array}$} \\
\hline & Carbon & Oxygen & Titanium & \\
\hline Commercial TiC & 34 & 43 & 23 & 0.68 \\
\hline Commercial TiC ion milled for $8 \mathrm{~min}$ & 40 & 20 & 40 & 1 \\
\hline
\end{tabular}

$455.6 \mathrm{eV})$ or $\mathrm{TiC}(454.2 \mathrm{eV})$ but not as $\mathrm{TiO}_{2}(458 \mathrm{eV}) .^{35} \mathrm{The}$ $\mathrm{XRD}$ data for the precursor pyrolyzed to $900^{\circ} \mathrm{C}$ discussed below also suggest that the material is crystalline TiN.

(D) XRD Patterns: Figure 4(A) shows powder XRD patterns for precursors pyrolyzed to $400^{\circ}, 900^{\circ}, 1100^{\circ}$, and $1200^{\circ} \mathrm{C}$ with a dwell time of $1 \mathrm{~h}$. All samples heated to temperatures of $>400^{\circ} \mathrm{C}$ have been pyrolyzed at a rate of $2^{\circ} \mathrm{C} / \mathrm{min}$ in argon to a temperature of $500^{\circ} \mathrm{C}$ and then at a rate of $10^{\circ} \mathrm{C} / \mathrm{min}$ in argon to higher temperatures. The XRD data show peaks attributable to crystalline TiN (ICDD File Card No. 38-1420).

The broad peaks and poor intensities, as seen in the sample pyrolyzed to $400^{\circ} \mathrm{C}$, suggest that considerable material is either amorphous or nanocrystalline. In Fig. 4(A), as the pyrolysis temperature increases, the XRD peak intensities increase and the peak widths decrease, indicating a greater degree of crystallinity and/or grain growth. Because TiC and TiN are almost isomorphous, the XRD peaks for the commercial powders can only be differentiated by careful examination of selected reflections (see below). Furthermore, the formation of a TiN/C solid solution would diminish the unit-cell parameter differences, which makes distinguishing between the two materials even more difficult. Thus, the formation of a TiN/C solid solution cannot be excluded based solely on XPS and XRD data. However, the $\sim 1: 1$ Ti:N ratios found (by XPS and chemical analysis) at $900^{\circ} \mathrm{C}$ suggest mostly pure $\mathrm{TiN}$ with free carbon, unless some nitrogen is present as carbon nitride, which we find

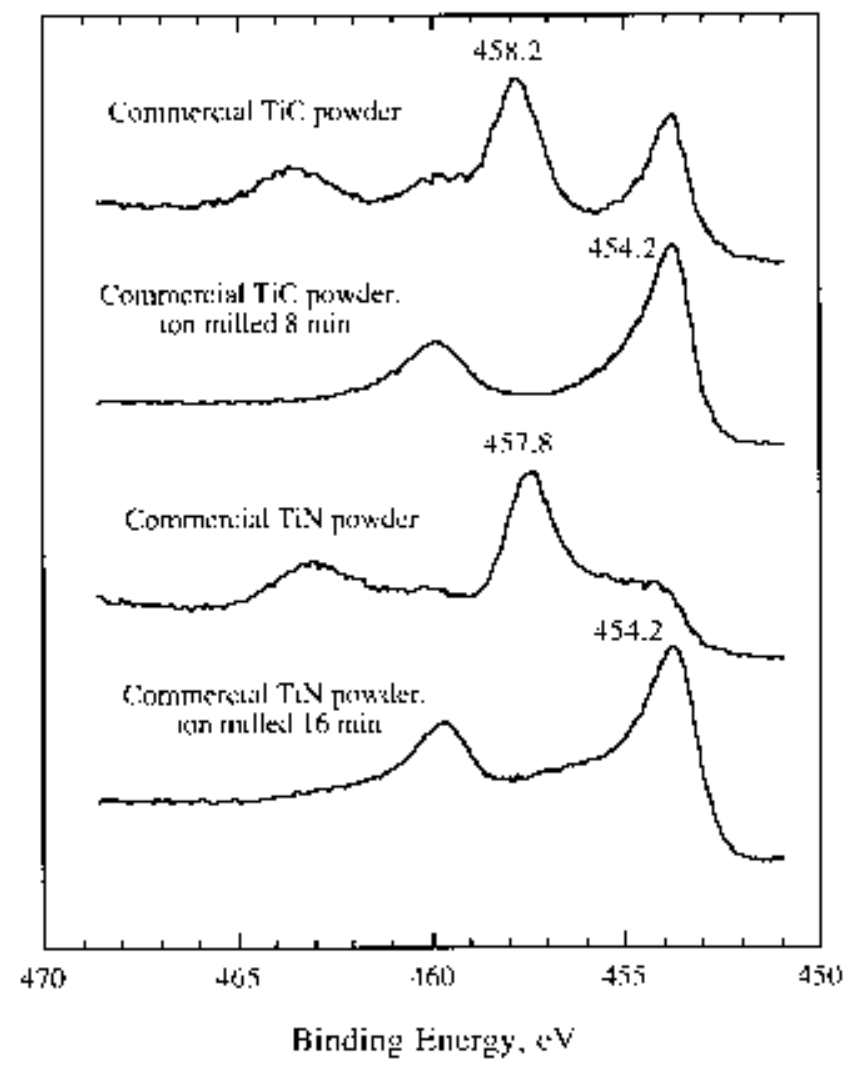

(A) unacceptable based on the carbon nitride literature. ${ }^{34}$ Moreover, the TGA oxidation studies (see above) support our contention that at $900^{\circ} \mathrm{C}$, the carbon is present as free carbon. A third argument comes from the TGA oxidation studies at $1200^{\circ} \mathrm{C}$ and the XRD analyses that follow.

Figure 4(A) also shows the XRD data for a commercial TiC powder, with peak positions corresponding to ICDD File Card No. 32-1383. Comparing the peak positions of the commercial TiN, the TiN precursor pyrolyzed to $900^{\circ} \mathrm{C}$, and the commercial TiC powders, the $\mathrm{TiC}$ peaks are found at angles $\sim 1^{\circ} 2 \theta$ lower than those for $\mathrm{TiN}$ and for the maximum for the pyrolyzed samples. This is best illustrated using the Fig. 4(B) data for the (200) peak at $42.6^{\circ} 2 \theta$, suggesting that this material is TiN. However, Fig. 4 (B) also shows that, at $1200^{\circ} \mathrm{C}$, this peak shifts to $42.1^{\circ} 2 \theta$, which is closer to the (200) peak of $\mathrm{TiC}$ at $41.2^{\circ} 2 \theta$ (ICDD File Card No. 32-1383, position $41.7^{\circ} 2 \theta$ ). Most likely, some carbon displaces nitrogen in the TiN lattice, shifting the unit-cell parameters closer to those of $\mathrm{TiC}$ at the higher pyrolysis temperatures. These results are in accord with our TGA oxidation findings that suggest $\sim 6 \%$ of the $24.6 \%$ of carbon that is remaining at $1200^{\circ} \mathrm{C}$ is present as the carbide.

\section{(3) Coating Studies}

As described above, graphite fibers were dip coated in TiN precursor solutions $(0.5,1$, and 2 equivalent wt $\% \mathrm{TiN})$ and then pyrolyzed to selected temperatures in argon. These studies were

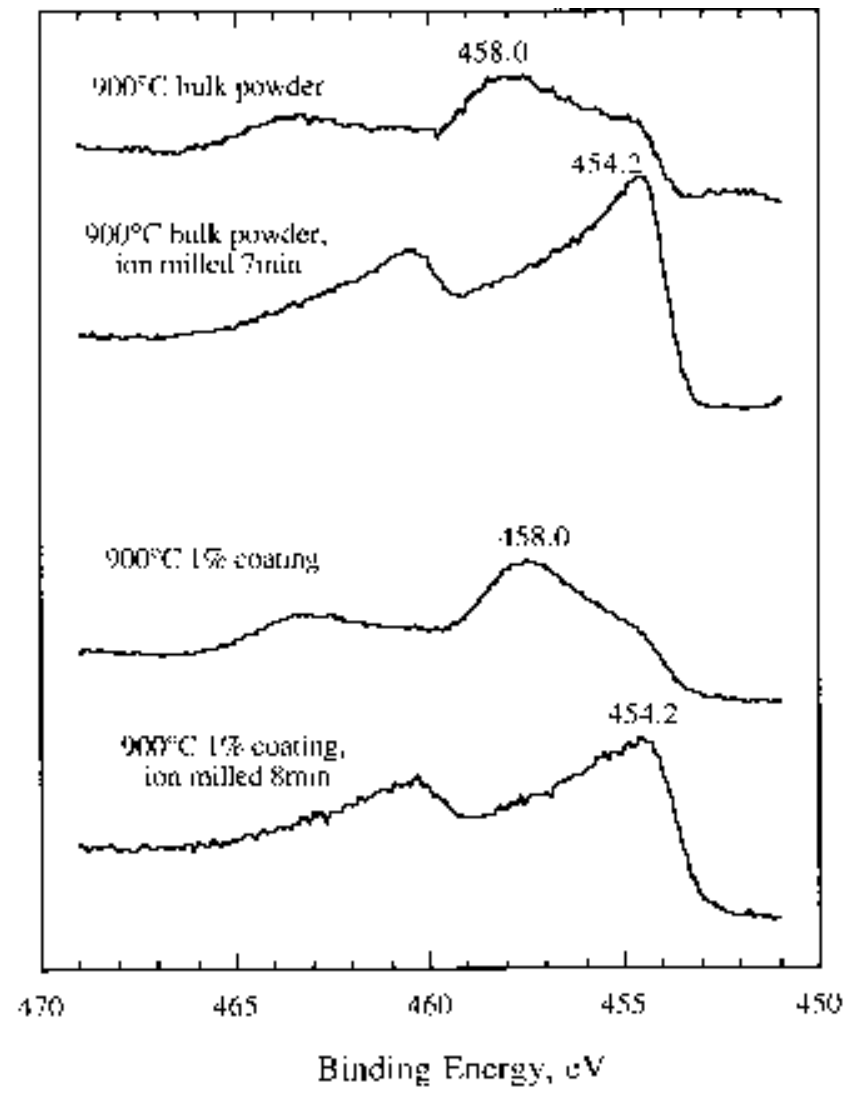

(B)

Fig. 3. XPS data for commercial powders: (A) pyrolyzed precursor, and (B) graphite fibers coated with 1 equivalent wt\% TiN and pyrolyzed to $900^{\circ} \mathrm{C}$ for $1 \mathrm{~h}$ in $\operatorname{argon}$. 


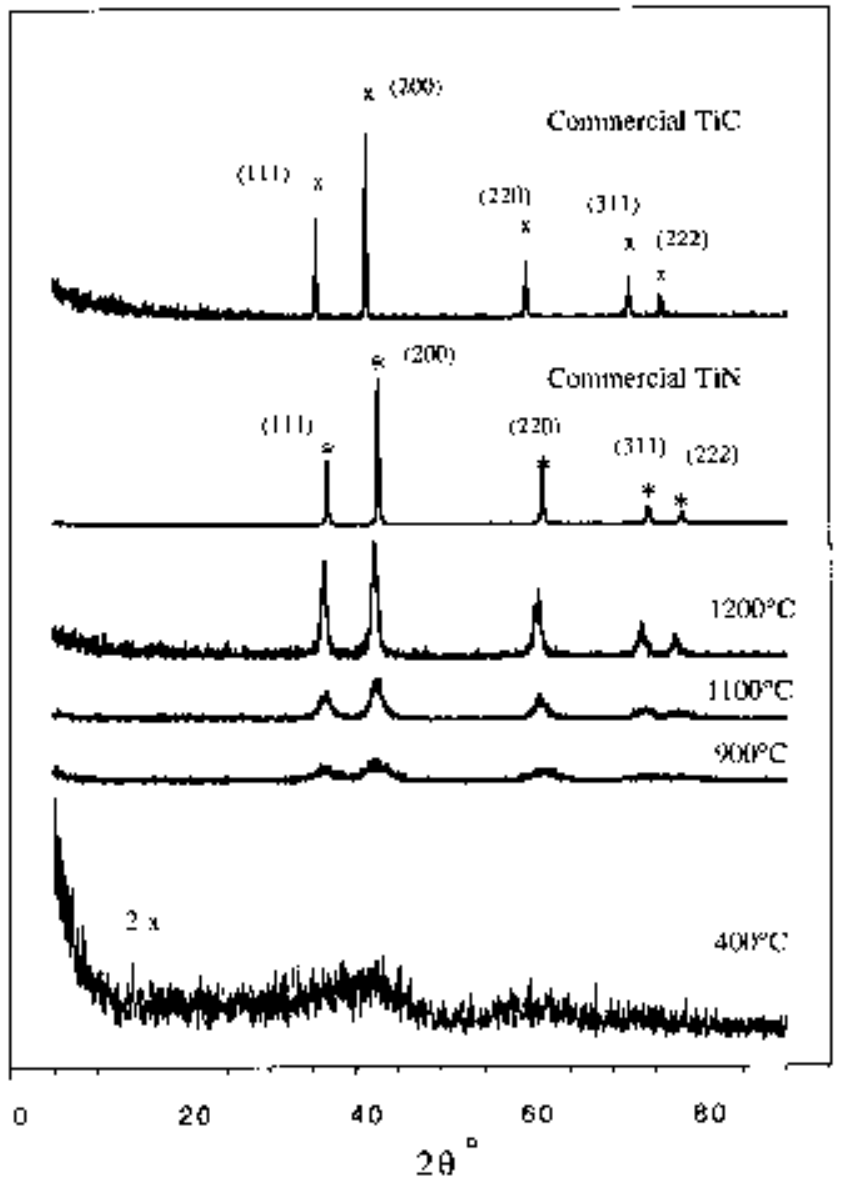

(A)

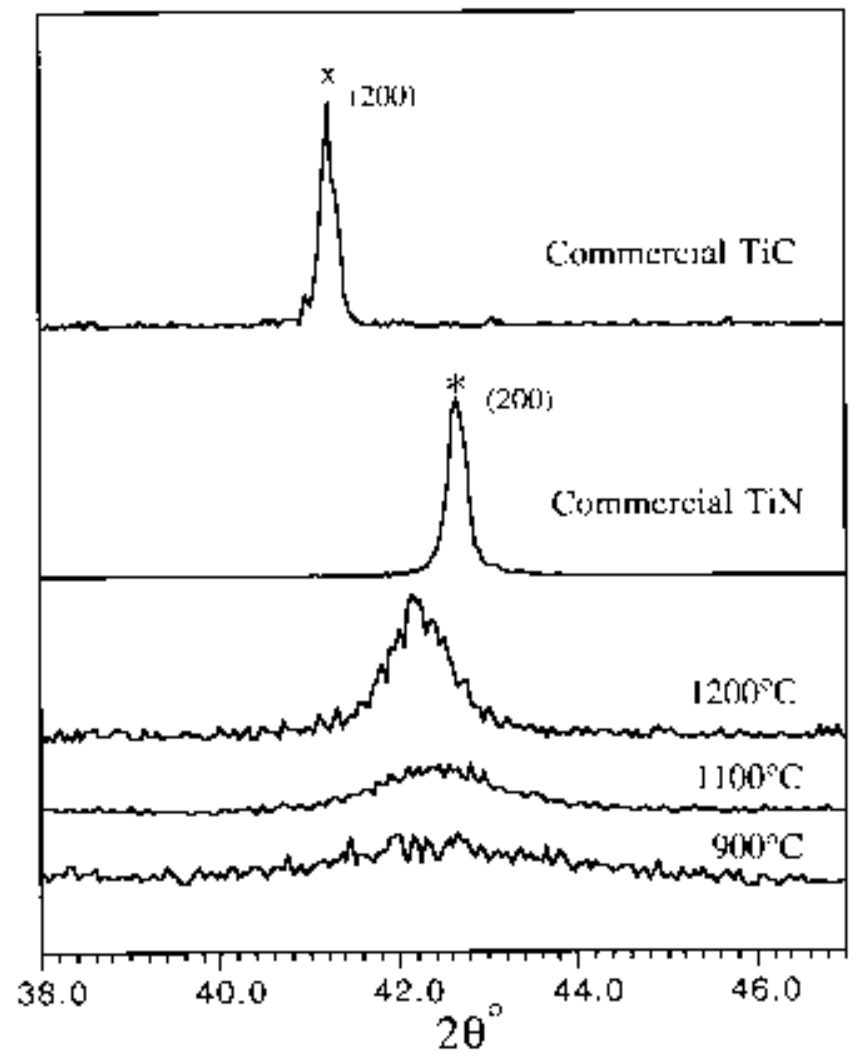

(B)

Fig. 4. (A) XRD for precursor solutions pyrolyzed to $400^{\circ}, 900^{\circ}, 1100^{\circ}$, and $1200^{\circ} \mathrm{C}$, compared with the data for commercial TiN and TiC powders; (B) expanded view of the $38^{\circ}-47^{\circ} 2 \theta$ region shown in Fig. 4(A). Symbols "*" and "x" correspond to TiN (ICDD File Card No. 38-1420) and TiC (ICDD File Card No. 32-1383), respectively.

conducted to answer two questions. The first question is whether the coating solution can provide TiN coatings on graphite fibers. To address this question, XPS analyses of coated and pyrolyzed graphite fiber were conducted. The second question is what is the best processing route, including the concentration of the coating solution and the temperature of pyrolysis, to obtain the best coating properties. One important coating property is oxidation resistance. The oxidationresistance properties for fibers processed via different routes were evaluated using TGA by holding the fibers at $700^{\circ} \mathrm{C}$ for $2 \mathrm{~h}$ in air. The coatings were evaluated by SEM to detect the presence of defects and to examine the microstructure and the thickness.

(A) Pyrolysis Temperature Studies: The bulk material studies suggest that microcrystalline TiN, contaminated with free carbon, is obtained at $900^{\circ} \mathrm{C}$, based on the XPS and chemical analyses, which indicate a Ti:N ratio of $\sim 1$, almost the same as in pure TiN. At $1200^{\circ} \mathrm{C}$, based on the bulk XPS and CHN results, the coating is more likely to be a TiCN coating, albeit somewhat more crystalline. To understand which coatings provide better oxidation resistance, the coatings pyrolyzed to $900^{\circ}$ and $1200^{\circ} \mathrm{C}$ were compared.

(B) Graphite Fibers Coated with 1 equivalent wt\% TiN Precursor and Pyrolyzed to $900^{\circ} \mathrm{C}$ in Argon: Figure 5 shows a micrograph of desized graphite fibers. The fiber diameter is $9 \pm 1 \mu \mathrm{m} .{ }^{4}$ Cross sections of the fiber reveal striations associated with the orientation of the mesophasic pitch used to produce the fibers. After dip coating and pyrolysis, no visible changes in the fiber diameter are observed. Figure 6(A) shows a graphite fiber coated with a 1 equivalent wt $\%$ TiN precursor. At the lower right edge of the fresh-cut cross section, the debonded "skin" indicates a coating thickness of $0.1-0.2 \mu \mathrm{m}$. Figure $6(\mathrm{~B})$ provides a better view of the surface, which appears to be smooth and uniform; i.e., no cracks or pores are visible and the coating does not appear to debond from the surface. Hence, under these processing conditions, the polymer precursor coats fibers effectively and densifies uniformly on pyrolysis; the resulting ceramic coating wets the surface following pyrolysis.

XPS data for as-formed fiber coatings and for coated fibers that have been ion milled for $8 \mathrm{~min}$ are presented in Table V. The Ti:N ratio is 1.2:1 for the sample without ion milling and 1.6:1 for the sample that has been ion milled for $8 \mathrm{~min}$. Commercial TiN gives values of 1.4:1, even after ion milling. Note that for the ion-milled bulk precursor, we observe a Ti:N value of $1: 1$, which is confirmed by chemical analysis. However, as noted above, XPS analyses of powders are assumed to be somewhat inexact. Consequently, these results, considered in toto, suggest that the coating consists primarily of TiN and carbon; quantification of the amounts of each is not possible. As with the bulk analyses, some oxygen also is observed and likely results from surface absorption, because the pyrolyzed fibers were handled in air. Figure 3(B) shows the Ti $2 p_{3 / 2}$ binding-energy profiles for fresh surfaces with and without ion milling. These profiles appear to be very similar to the bulk precursor profiles. No changes in the peak positions are observed. Without ion milling, the binding energy observed is $458.0 \mathrm{eV}$, the same as the bulk sample data, and indicates the presence of $\mathrm{TiO}_{2}$ on the coating surface. Recall that XPS analyses provide information to depths of 30-50 A only. ${ }^{35}$ Similar to the behavior of the bulk precursor, after ion milling for $8 \mathrm{~min}$, the Ti $2 p_{3 / 2}$ peak position moves to $454.2 \mathrm{eV}$, which suggests the bonding is mainly TiN (454.8 eV, $455.6 \mathrm{eV})$, with carbon 


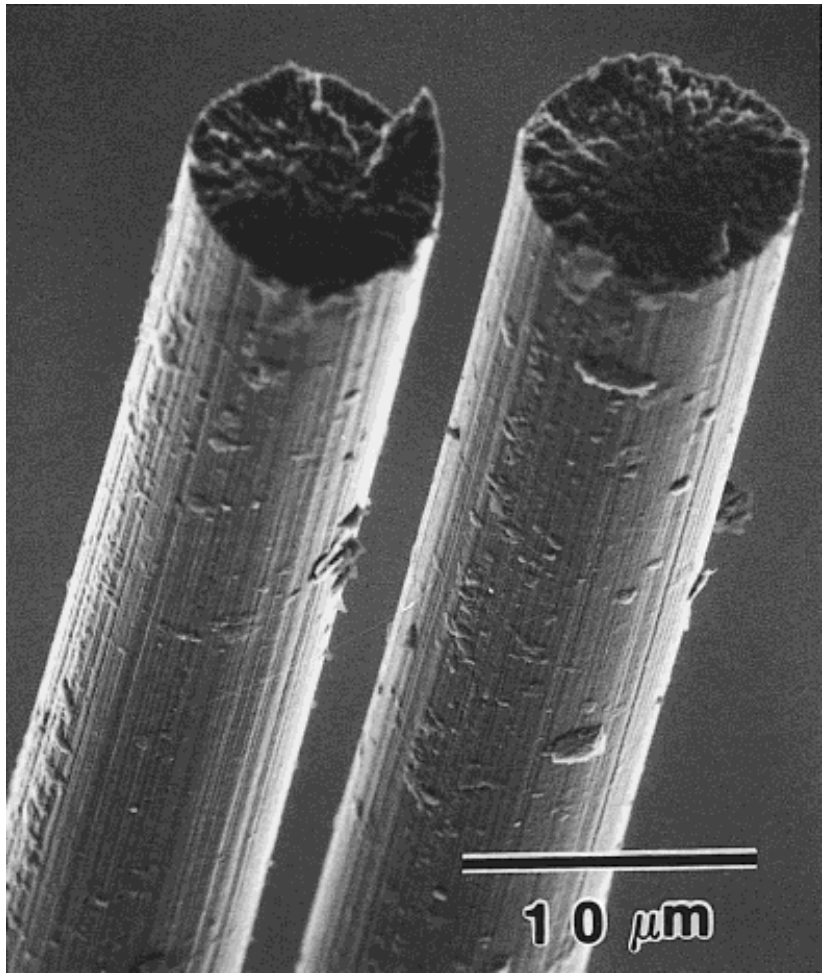

Fig. 5. SEM micrograph of a graphite fiber desized by heating in argon to $900^{\circ} \mathrm{C}$.

contamination. ${ }^{35}$ Analyses of the coatings processed at $1200^{\circ} \mathrm{C}$ also are similar to the bulk studies.

(C) Graphite Fibers Coated with 1 equivalent wt\% TiN Precursor and Pyrolyzed to $1200^{\circ} \mathrm{C}$ in Argon: The higher degree of crystallinity obtained at $1200^{\circ} \mathrm{C}$ and the potential

\section{(A)}

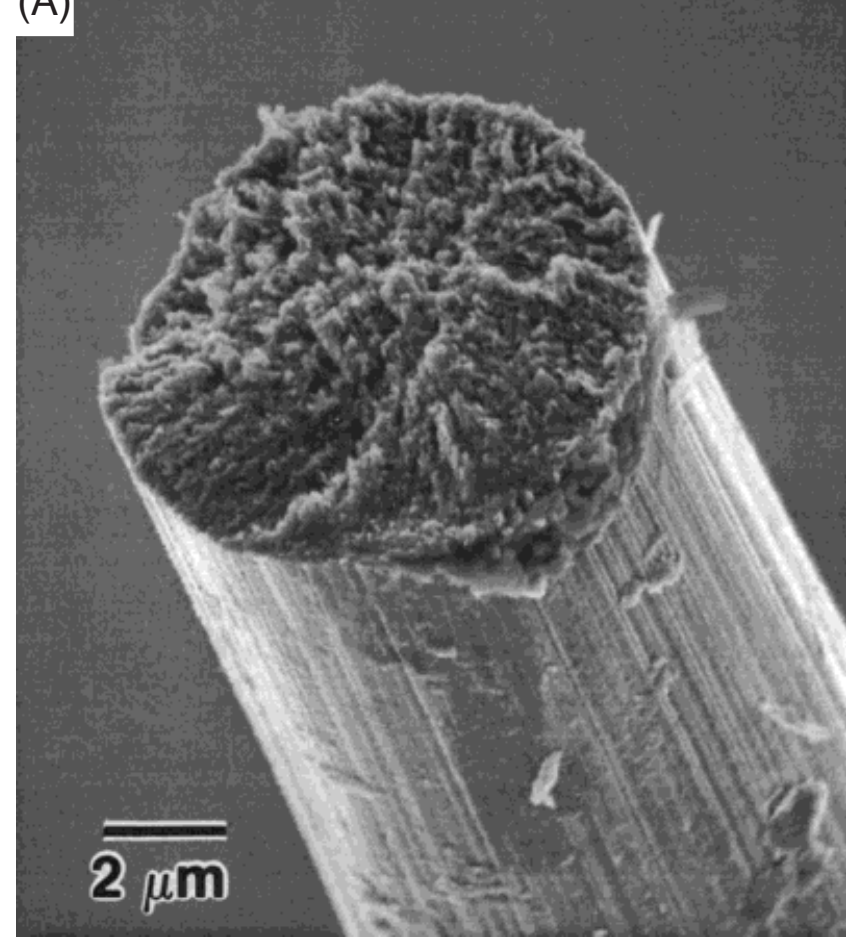

formation of $\mathrm{TiCN}$ rather than $\mathrm{TiC}$ coatings have prompted studies to ascertain whether improved coating properties could be obtained at $1200^{\circ} \mathrm{C}$. Figure 7 shows an SEM micrograph of a graphite-fiber cross section coated with 1 equivalent wt $\%$ TiN, revealing a cracked (flawed) coating. Furthermore, the fiber surfaces exhibit a mottled texture, wherein the fiber striations are clearly visible between beads of material. A highermagnification image (at $20000 \times$; see Fig. 8) strongly suggests that dewetting has occurred. These beads are not observed for coatings pyrolyzed to $900^{\circ} \mathrm{C}$ (Fig. 6(B)). The XPS Ti $2 p_{3 / 2}$ binding-energy profile for these surfaces (Fig. 3(B)) still exhibits peak maxima consistent with the presence of TiN/TiC or TiCN, although some $\mathrm{TiO}_{2}$ is present on surfaces that have not been ion milled. One possible explanation for dewetting is that, at higher temperatures, crystallization, coupled with the alleviation of compressive stresses created during the initial precursor-to-ceramic transformation process, lead to grain growth with dewetting.

(D) Oxidation Resistance of TiN-Coated Graphite Fibers Pyrolyzed to Different Temperatures: To establish the uniformity of the coatings and to develop a simple test of their reactivity, as measured by oxidation resistance, TGA oxidation studies were conducted using isothermal heating. Figure 9 shows that, on heating at a rate of $50^{\circ} \mathrm{C} / \mathrm{min}$ in air to a temperature of $700^{\circ} \mathrm{C}$, followed by an isothermal hold, uncoated fiber tows oxidize completely in $80 \mathrm{~min}$. In contrast, fiber tows coated with 1 equivalent wt $\%$ TiN solutions and pyrolyzed to $900^{\circ} \mathrm{C}$ reproducibly retained $\sim 55 \%$ of their initial weight at the end of the test (Fig. 9), indicating improved oxidation resistance. Fibers that were coated identically but heat treated to $1200^{\circ} \mathrm{C}$ exhibited lower oxidation resistance (Fig. 10). The inconsistent oxidation profiles that are shown suggest that coating integrity is lost at $1200^{\circ} \mathrm{C}$, as expected from the SEM studies. Oxidation resistance similar to that of the fibers processed at $900^{\circ} \mathrm{C}$ was obtained in related studies with $\mathrm{SiO}_{x} \mathrm{C}_{y}$, mullite, and $\mathrm{SiC}$ coatings. ${ }^{4,5,36}$

(E) TiN Solution Concentration Studies: Three different TiN solution concentrations- $-0.5,1$, and 2 equivalent $\mathrm{wt} \%-$

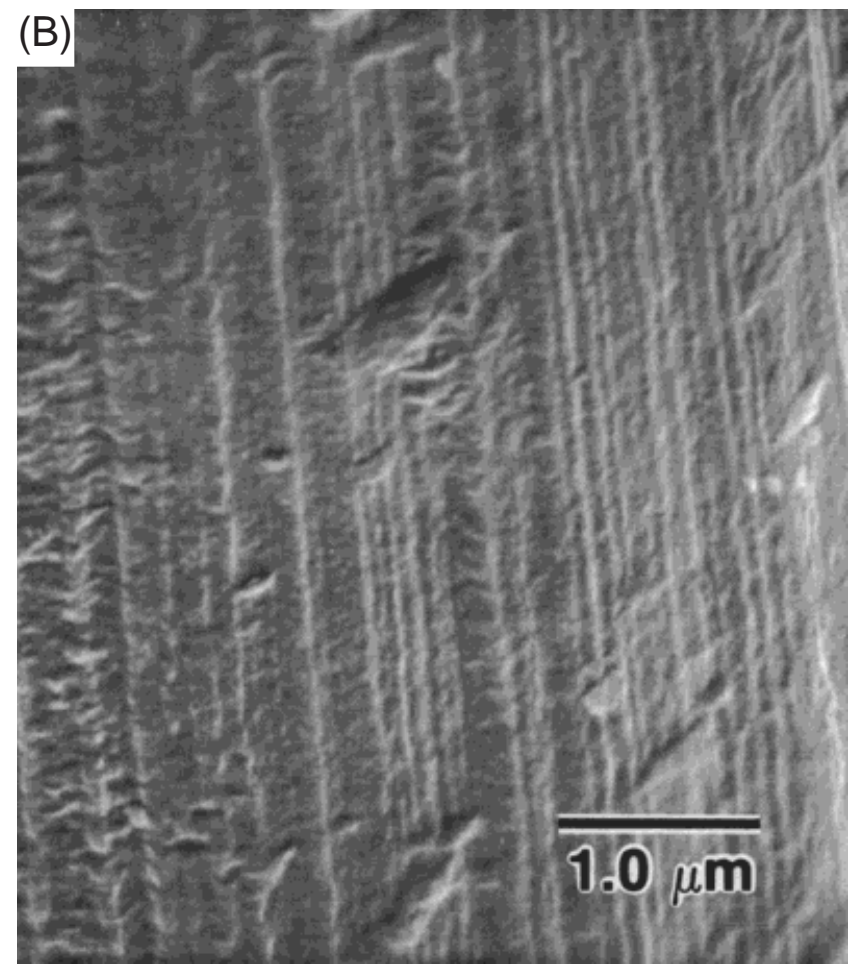

Fig. 6. (A) SEM micrograph of a cross section of a graphite fiber coated with 1 equivalent wt $\%$ TiN and pyrolyzed to $900^{\circ} \mathrm{C}$ for $1 \mathrm{~h}$ in argon; (B) higher-magnification view of the area in Fig. 6(A). 
Table V. XPS Data for Graphite Fibers Coated with 1 Equivalent wt\% TiN and Pyrolyzed to $900^{\circ} \mathrm{C}$

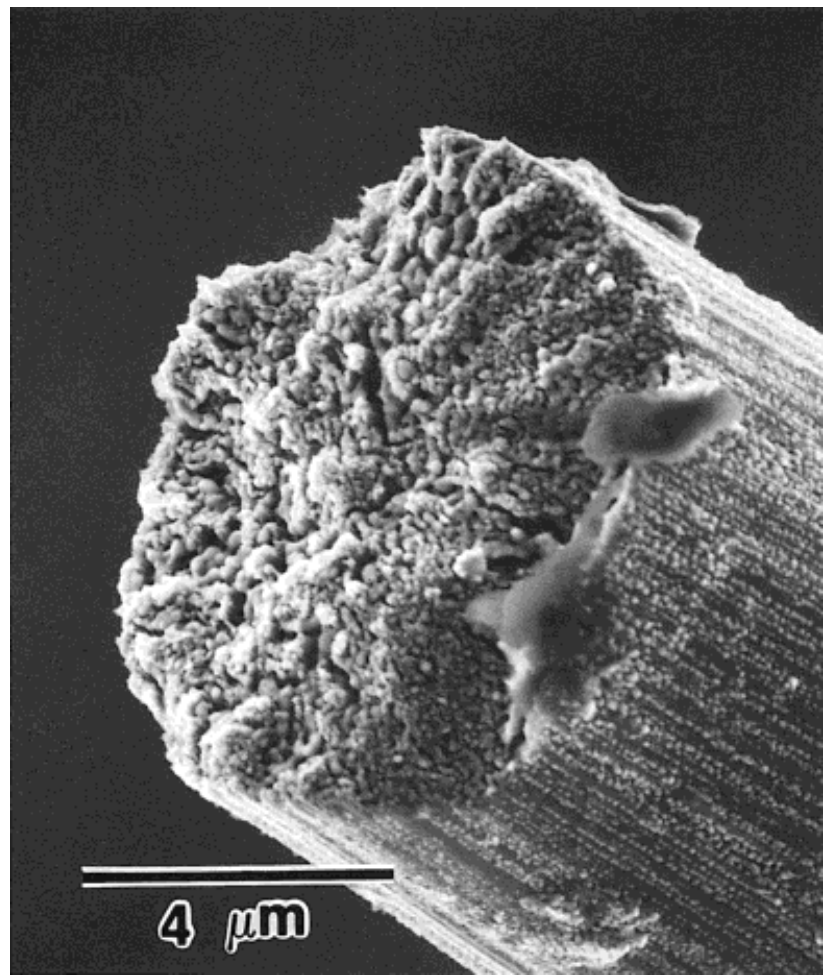

Fig. 7. SEM micrograph of a graphite fiber coated with 1 equivalent wt $\%$ TiN and pyrolyzed to $1200^{\circ} \mathrm{C}$.

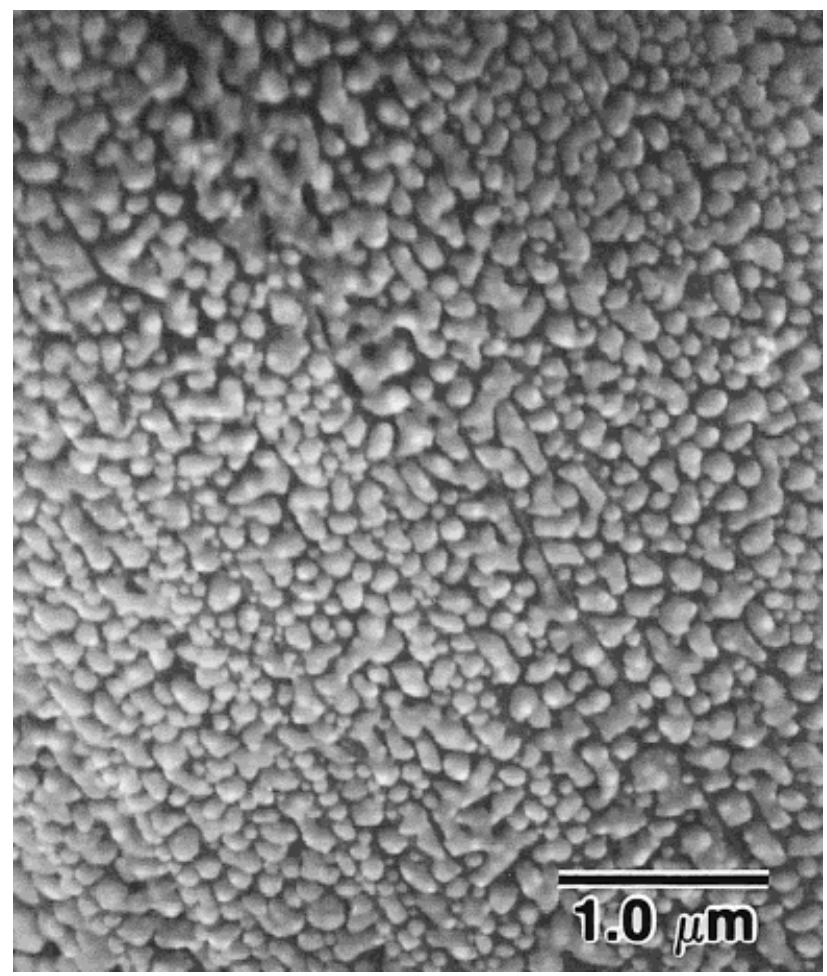

Fig. 8. SEM micrograph, at a magnification of $20000 \times$, of a graphite fiber coated with 1 equivalent wt $\%$ TiN and pyrolyzed to $1200^{\circ} \mathrm{C}$.

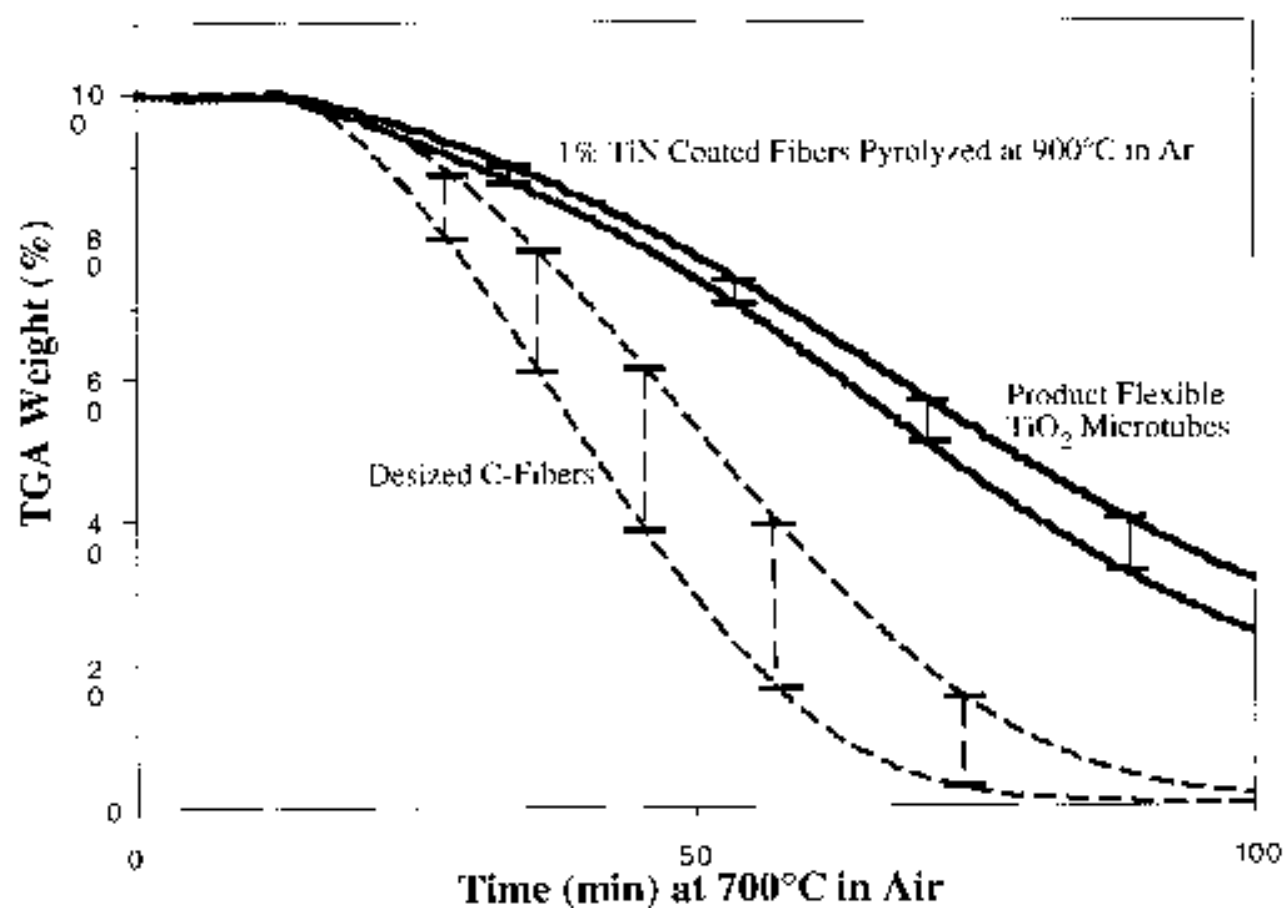

Fig. 9. TGA plots for graphite fibers coated with 1 equivalent wt $\% \mathrm{TiN}\left(900^{\circ} \mathrm{C}\right)$ heated to $700^{\circ} \mathrm{C}$ in air. 


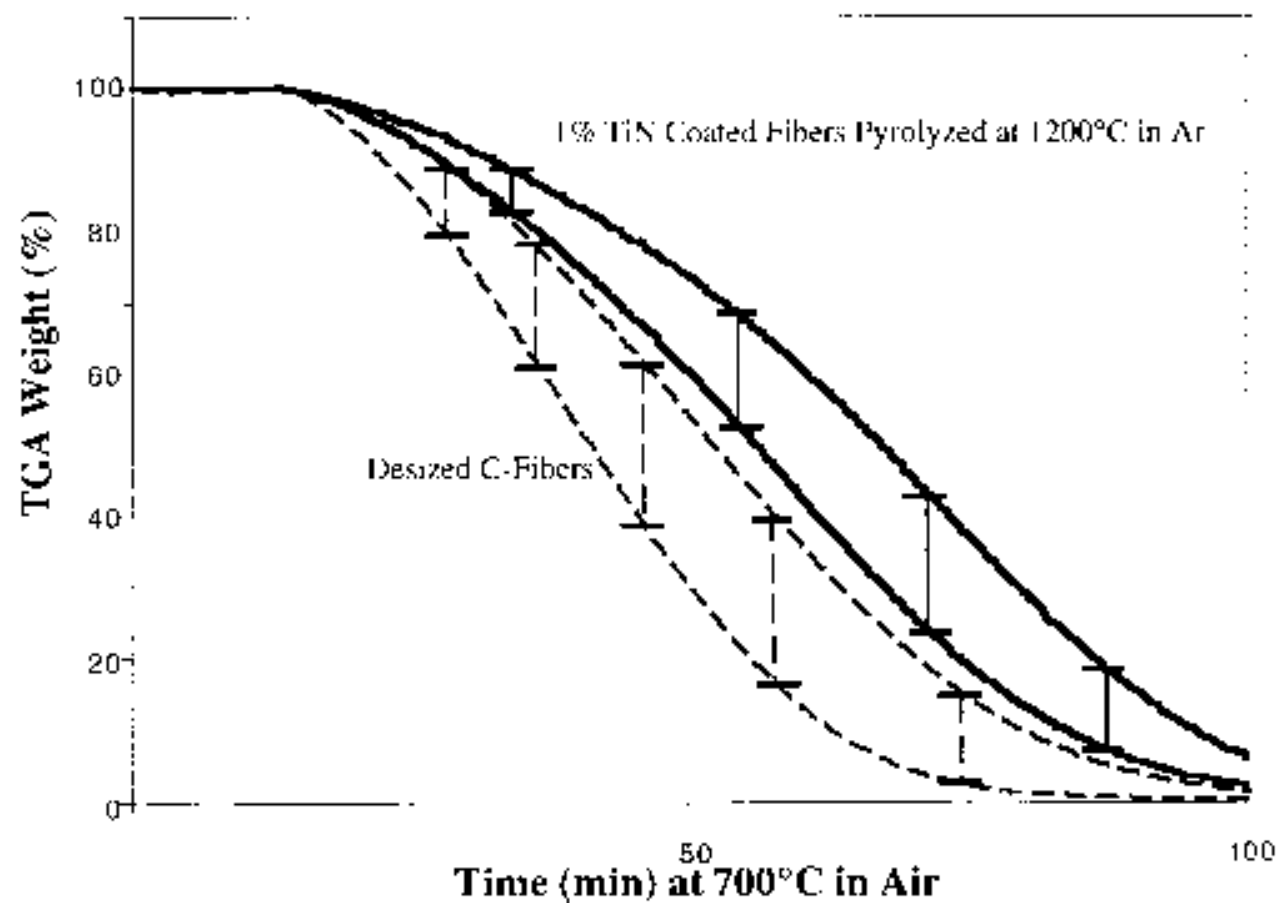

Fig. 10. TGA plots for graphite fibers coated with 1 equivalent wt $\% \operatorname{TiN}\left(1200^{\circ} \mathrm{C}\right)$ heated to $700^{\circ} \mathrm{C}$ in air.

were studied. The coating properties were again evaluated by isothermal oxidation studies at $700^{\circ} \mathrm{C}$ for $3 \mathrm{~h}$ in air. Fiber tows coated with 0.5 equivalent wt $\%$ TiN and processed at $900^{\circ} \mathrm{C}$ exhibited erratic oxidation behavior (Fig. 11). Some tows behaved similarly to the uncoated ones and others retained $>50 \%$ of their original mass at the end of the test (120 min), as observed for the tows coated with 1 equivalent wt $\%$ TiN. This behavior can be attributed to incomplete or insufficient coating of the fibers. The 2 equivalent wt $\%$ TiN coatings (pyrolyzed to $900^{\circ} \mathrm{C}$ for $1 \mathrm{~h}$ in argon) provided good, but erratic, oxidation resistance. In this instance, the average coating appears to have been too thick $(0.2-0.4 \mu \mathrm{m})$, leading to process-related cracking, as shown in Fig. 12. The cracks permitted the ingress of oxygen, leading to rapid oxidation.

The Fig. 9 TGA behavior of graphite-fiber tows coated with 1 equivalent wt $\% \mathrm{TiN}\left(900^{\circ} \mathrm{C}\right)$ (shown in Fig. 9) must be treated as a lower limit for fiber-coating oxidation resistance, because some portion of the coated fiber ends crack during processing; the coatings at these ends are thicker than average (Fig. 13). For these fibers, oxidation starts from the fiber ends. Figure 14 shows the end of a graphite fiber coated with 1 equivalent wt $\%$ TiN and pyrolyzed to $900^{\circ} \mathrm{C}$ after heating at $650^{\circ} \mathrm{C}$ for $3 \mathrm{~h}$ in

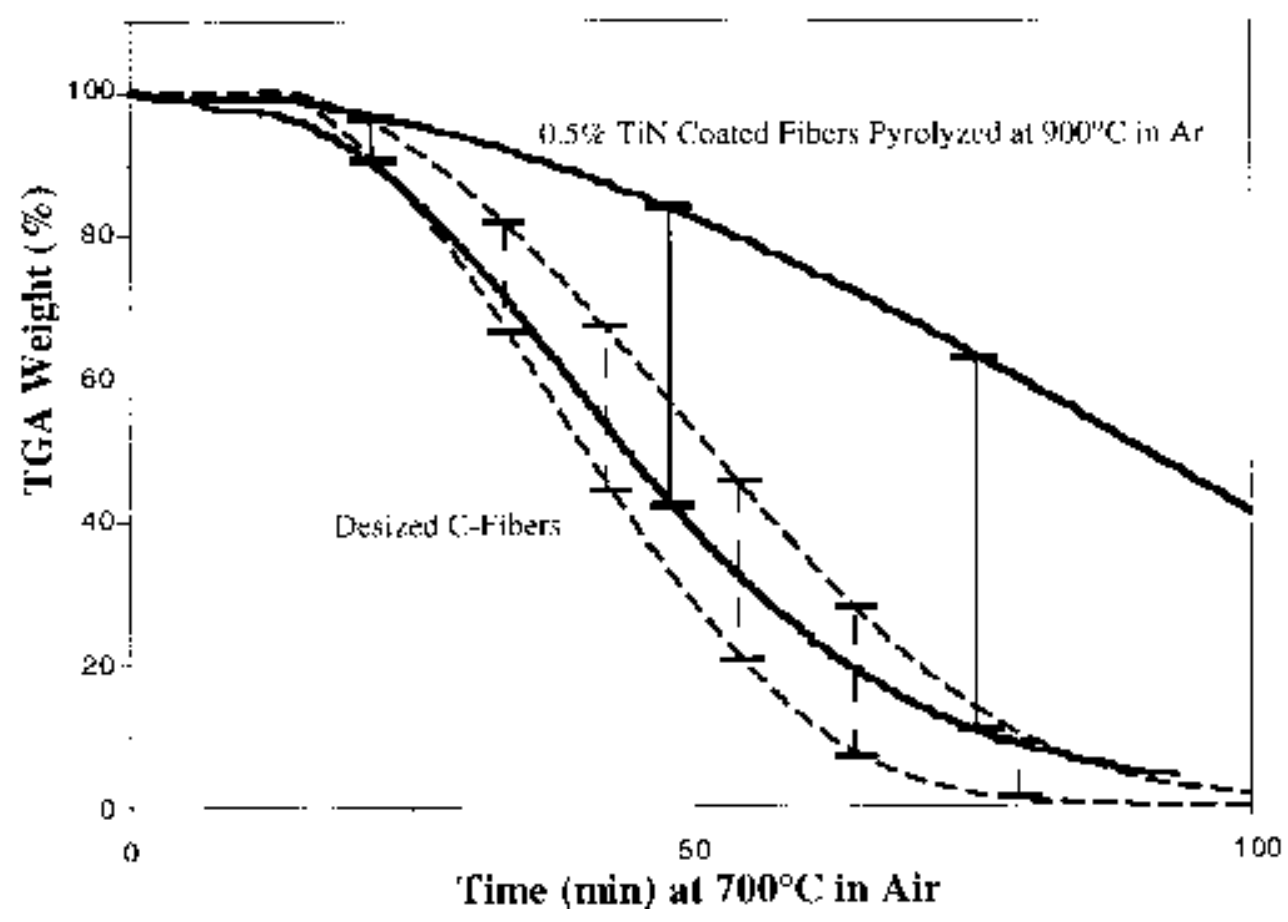

Fig. 11. TGA plots for graphite fibers coated with 0.5 equivalent wt $\% \operatorname{TiN}\left(900^{\circ} \mathrm{C}\right)$ heated to $700^{\circ} \mathrm{C}$ in air. 


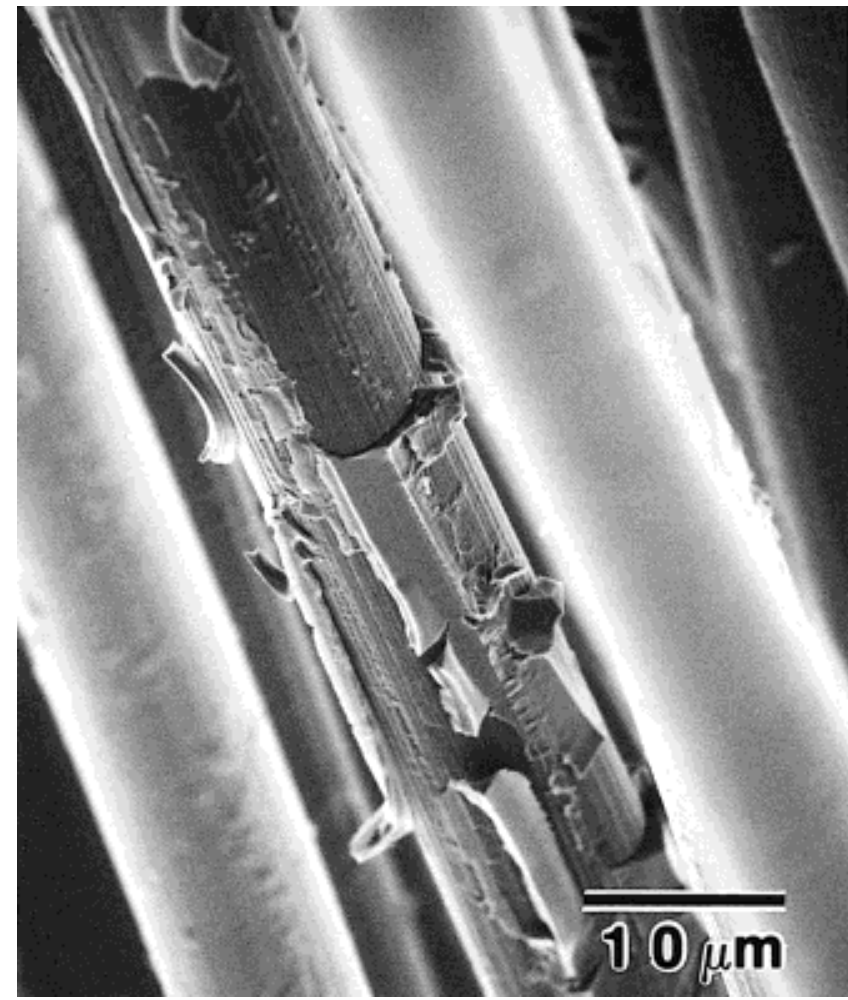

Fig. 12. SEM micrograph of a graphite fiber coated with 2 equivalent wt $\%$ TiN and pyrolyzed to $1200^{\circ} \mathrm{C}$ for $1 \mathrm{~h}$ in argon.

air. The hollow structure indicates that the graphite fiber oxidizes, leaving behind the skin of the ceramic coating. However, in the middle of the same fiber section, the graphite fiber remains unoxidized, indicating the actual oxidation resistance is likely higher than determined by TGA (Fig. 15).

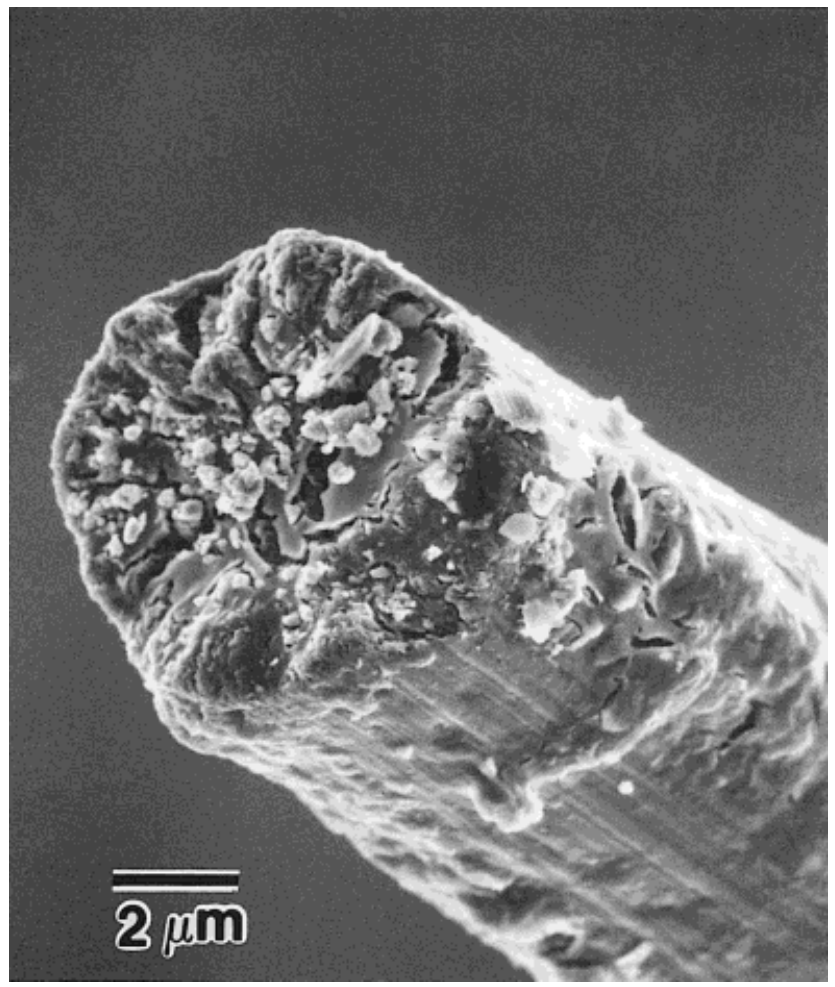

Fig. 13. SEM micrograph of a graphite fiber coated with 1 equivalent wt $\% \mathrm{TiN}$ and pyrolyzed to $900^{\circ} \mathrm{C}$ for $1 \mathrm{~h}$ in argon.

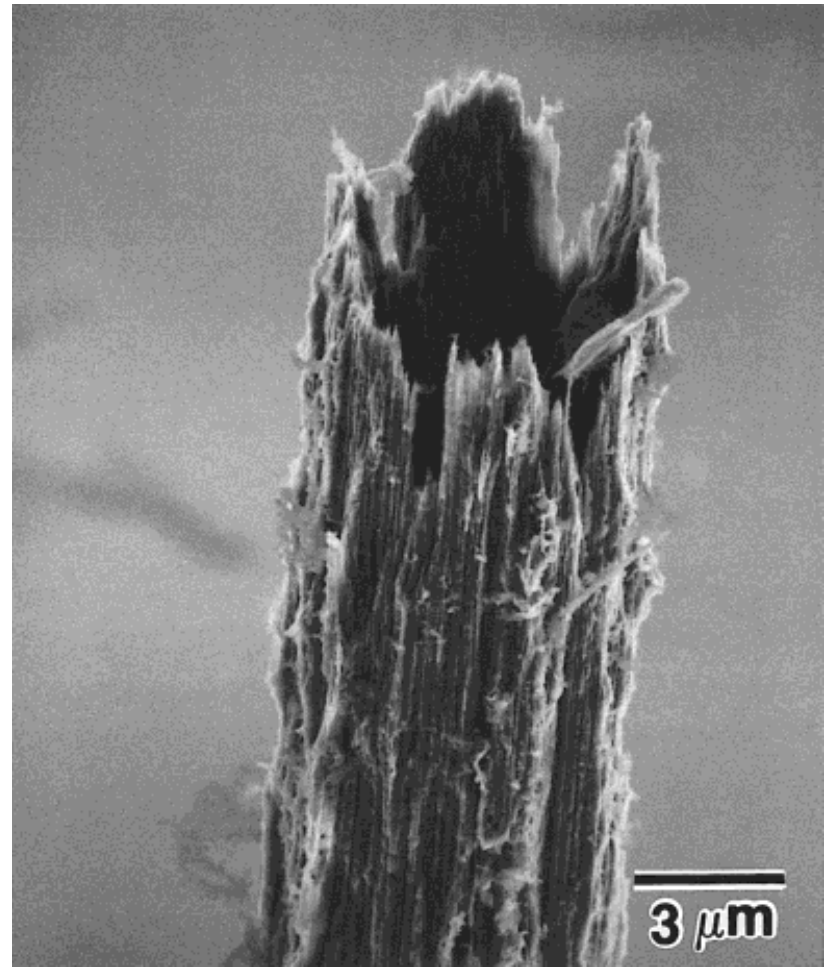

Fig. 14. SEM micrograph of an end of a graphite fiber coated with 1 equivalent wt $\%$ TiN and pyrolyzed to $900^{\circ} \mathrm{C}$ that has been oxidized at $650^{\circ} \mathrm{C}$ for $3 \mathrm{~h}$ in air.

\section{Summary}

A processable, easily prepared TiN precursor, $\left[\mathrm{Ti}\left(\mathrm{NMe}_{2}\right)_{x}\right.$ $\left.\left(\mathrm{NCHMe}_{2}\right)_{4-2 x}\right]_{n}$ was synthesized and then characterized by TGA, chemical analysis, and NMR. Based on these analyses, the general molecular structure is suggested to be

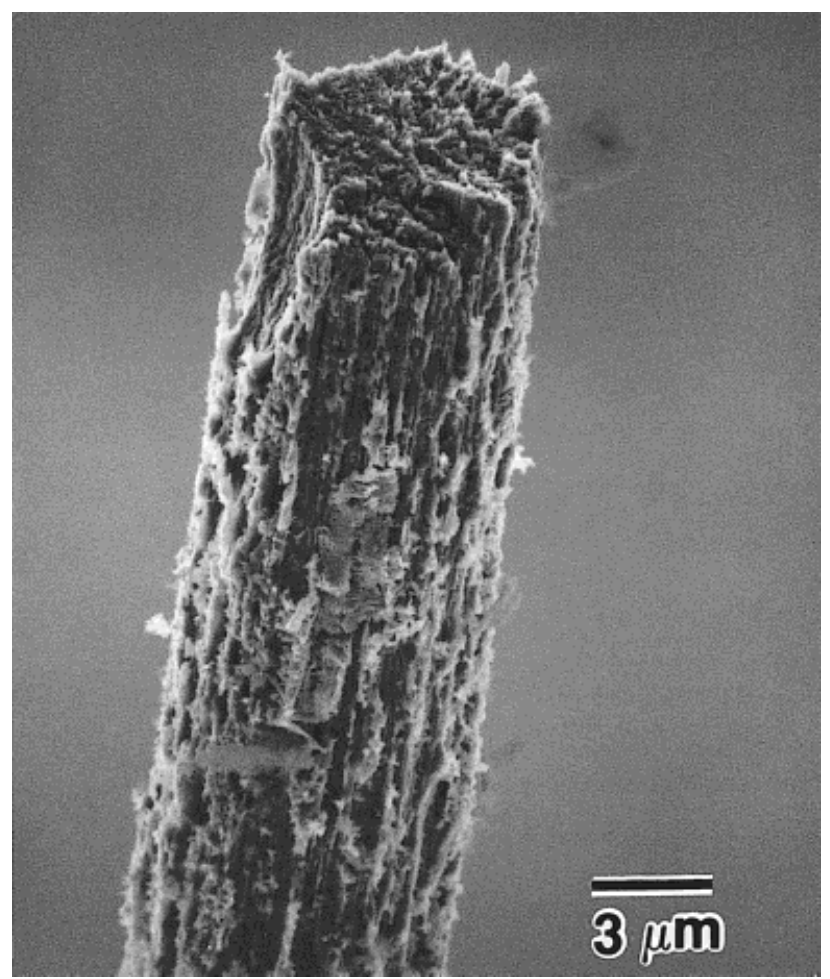

Fig. 15. SEM micrograph of the middle of a graphite fiber coated with 1 equivalent wt $\% \mathrm{TiN}$ and pyrolyzed to $900^{\circ} \mathrm{C}$ that has been oxidized at $650^{\circ} \mathrm{C}$ for $3 \mathrm{~h}$ in air. 


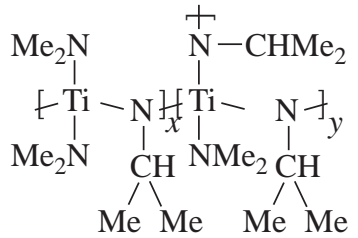

The phase and microstructural evolution that occurs on pyrolytic transformation of the precursor to a ceramic material has been followed by XRD, CHN, and XPS. On heating to temperatures of $\geq 900^{\circ} \mathrm{C}$, a microcrystalline material is generated that is suggested by XPS and XRD to be primarily TiN. The Ti:N ratio at $900^{\circ} \mathrm{C}$ is $\sim 1: 1$; however, chemical analysis, TGA oxidation studies, and XPS indicate the presence of 22-24 wt $\%$ of free carbon. For material pyrolyzed to $1200^{\circ} \mathrm{C}$ for $1 \mathrm{~h}$ in argon, the Ti: $\mathrm{N}$ ratio is no longer $1: 1$, suggesting the formation of $\mathrm{TiC}$ and/or TiCN; the XRD data also suggest a powder pattern indicative of a $\mathrm{TiN}-\mathrm{TiC}$ solid solution.

Three hexane precursor solutions were prepared, containing $0.5,1$, and 2 equivalent wt $\%$ TiN. Graphite fiber tows were dip coated in these solutions and pyrolyzed to $900^{\circ} \mathrm{C}$ for $1 \mathrm{~h}$ in $\operatorname{argon}$ or $1200^{\circ} \mathrm{C}$ for $1 \mathrm{~h}$ in $\operatorname{argon}$ (for $1 \mathrm{wt} \%$ TiN only). Coating composition and integrity were evaluated by XPS, SEM, and oxidation resistance. The best coatings were those obtained with the 1 equivalent wt $\%$ solutions and heated to $900^{\circ} \mathrm{C}$, as determined by the relative absence of pores or cracks, with a thickness of $0.1-0.2 \mu \mathrm{m}$.

The oxidation resistance of the resulting ceramic coatings was compared by following the weight loss in TGA at $700^{\circ} \mathrm{C}$ over a period of $2 \mathrm{~h}$. The TGA profiles demonstrated improved oxidation resistance after coating. The fiber tows coated with 1 equivalent $\mathrm{wt} \%$ TiN retained $>50 \%$ of their mass after $100 \mathrm{~min}$, whereas the fiber tows coated with 0.5 and 2 equivalent wt $\%$ TiN exhibited erratic oxidation behavior, because of processing flaws. Uncoated fiber tows oxidized fully after $80 \mathrm{~min}$.

\section{References}

'R. N. Singh, "Fiber-Matrix Interfacial Characteristics in a Fiber-Reinforced Ceramic-Matrix Composite," J. Am. Ceram. Soc., 72 [9] 1764-67 (1989).

${ }^{2}$ R. N. Singh and M. Sutcu, "Determination of Fiber-Matrix Interfacial Properties in Ceramic-Matrix Composites by a Fiber Push-out Technique," J. Mater. Sci., 26, 2547-56 (1991)

${ }^{3}$ (a) D. Hull, An Introduction to Composite Materials. Cambridge University Press, Cambridge, U.K., 1981. (b) A. G. Metcalfe and M. J. Klein, "Effect of the Interface on Longitudinal Tensile Properties"; pp. 125-68 in Interfaces in Metal Matrix Composites, Composite Materials, Vol. 1. Edited by A. G. Metcalfe. Academic Press, New York, 1974

${ }^{4}$ M. Harris, T. Chaudhary, L. Drzal, and R. M. Laine, "Silicon Oxycarbide Coatings on Graphite Fibers: Chemistry, Processing, and Oxidation Resistance," Mater. Sci. Eng. A, 195, 233-36 (1995).

${ }^{5}$ P. Kansal, "Mullite Coatings on Graphite Fibers: Precursor Synthesis, Processing, Characterization and Oxidation Resistance"; Ph.D. Dissertation. Department of Material Science and Engineering, University of Michigan, Ann Arbor, MI, 1996.

${ }^{6}$ A. P. Diwanji and I. W. Hall, "Fibre and Fibre-Surface Treatment Effects in Carbon/Aluminium Metal Matrix Composites," J. Mater. Sci., 27, 2093100 (1992)

${ }^{7}$ P. Ehrburger and E. Dallies-Labourdetle, "Inhibition of the Oxidation of Carbon Fibres and Composites," Tanso, 155, 359-64 (1992).

${ }^{8}$ (a) H.-M. Cheng, B.-L. Zhou, A. Kitahara, S. Akiyama, and K. Kobayashi, "Effect of Silicon Additions on Characteristics of Carbon Fiber Reinforced Aluminum Composites During Thermal Exposure," J. Mater. Res., 11 [5] 1284-92 (1996). (b) H.-M. Cheng, A. Kitahara, S. Akiyama, K. Kobayashi, Y. Uchiyama, and B.-L. Zhou, "Characteristics of Several Carbon FibreReinforced Aluminium Composites Prepared by a Hybridization Method," J. Mater. Sci., 29, 4342-50 (1994).

${ }^{9}$ B. J. Tan, L. Hwan, S. L. Suib, and F. S. Galasso, "Chemical Vapor Deposition TiN Coating on Silicon Carbide Coated Boron Fibers," J. Vac. Sci. Technol. A, 9 [4] 2196-203 (1991)

${ }^{10}$ (a) Y. Xie and P. M. A. Sherwood, "Coatings of Aluminum Oxide and Magnesium Oxide on Carbon Fiber Surfaces," Chem. Mater., 6, 650-57 (1994). (b) C. Vincent, H. Vincent, H. Mourichoux, and J. Bouix, "Characterization by XPS and SEM of Reactive Chemical Vapour Deposited Boron Carbide on Carbon Fibre," J. Mater. Sci., 27, 1892-900 (1992)

${ }^{11} \mathrm{~W}$. C. Oliver, C. J. McHargue, and S. J. Zinkle, "Thin Film Characterization Using a Mechanical Properties Microprobe"; pp. 185-96 in Metallurgical Coatings 1987, Vol. I. Edited by R. C. Krutenat. Elsevier, New York, 1987.

${ }^{12}$ E. Erturk and H.-J. Heuvel, "Adhesion and Structure of TiN Arc Coatings," Thin Solid Films, 153, 135-47 (1987).

${ }^{13}$ M. D. Sanctis, S. Pelletier, Y. Bienvenu, and H. Vincent, "Filamentary Preforms of Al-13 wt\% Si Alloy Reinforced with TiC-Coated and Pre-treated Carbon Fibres," J. Mater. Sci., 29, 356-65 (1994).
${ }^{14}$ R. M. Fix, R. G. Gordon, and D. M. Hoffman, "Synthesis of Thin Films by Atmospheric Pressure Chemical Vapor Deposition Using Amido and Imido Titanium(IV) Compounds as Precursors," Chem. Mater., 2, 235-41 (1990).

${ }^{15}$ (a) M.-A. Nicolet, "Diffusion Barriers in Thin Films," Thin Solid Films, 52, 415-43 (1978). (b) M. Wittmer, B. Studer, and H. Melchior, "Electrical Characteristics of TiN Contacts to N Silicon," J. Appl. Phys., 52 [9] 5722-26 (1981). (c) S. Kanamori, "Investigation of Reactively Sputtered TiN Films for Diffusion Barriers," Thin Solid Films, 136, 195-214 (1986).

${ }^{16} \mathrm{C}$. Y. Ting, "TiN Formed by Evaporation as a Diffusion Barrier Between Al and Si," J. Vac. Sci. Technol. B, 21 [1] 14-18 (1982).

${ }^{17} \mathrm{~J}$. R. Shapirrio, "Diffusion Barriers in Advanced Semiconductor Device Technology," Solid State Technol., 28 [10] 161-66 (1985).

${ }^{18}$ L. H. Dubois, B. R. Zegarski, and G. S. Girolami, "Infrared Studies of the Surface and Gas Phase Reactions Leading to the Growth of Titanium Nitride Thin Films from Tetrakis (dimethylamido) Titanium and Ammonia," J. Electrochem. Soc., 139 [12] 3603-609 (1992).

${ }^{19}$ (a) C. Russel, "Preparation and Pyrolysis of a Polymeric Precursor for the Formation of TiN-TiC Solid Solutions," Chem. Mater., 2, 241-44 (1990). (b) D. Seyferth and G. Mignani, "Preparation of Titanium Nitride and Titanium Carbonitride by the Preceramic Polymer Route," J. Mater. Sci. Lett., 7, 48788 (1988).

${ }^{20}$ (a) D. C. Bradley and I. M. Thomas, "Metallo-organic Compounds Containing Metal-Nitrogen Bonds, Part I. Some Dialkylamino-Derivatives of Titanium and Zirconium," J. Chem. Soc., 3857-61 (1960). (b) D. C. Bradley and E. G. Torrible, "Metallo-organic Compounds Containing Metal-Nitrogen Bonds, Part IV. Some Bis-(Primary Amino)-Titanium Compounds," Can. J. Chem., 41, 134-38 (1963). (c) C. T. Jekel-Vroegop and J. H. Teuben, "Monoalkyl and Nomoaryl-Amidotitanium Complexes," J. Org. Chem., 286, 309-15 (1985).

${ }^{21}$ (a) R. M. Laine, "Transition Metal Carbides and Process for Making Same," U.S. Pat. No. 4789534, Dec. 1988. (b) R. M. Laine, "Method of Preparing Metal Carbides and the Like and Precursors Used in Such Method," U.S. Pat. No. 4826666 , May 1989. (c) R. M. Laine, "Method of Preparing Coatings of Metal Carbides and the Like," U.S. Pat. No. 4906493 , March 1990.

${ }^{22}$ (a) J. N. Musher and R. G. Gordon, "Atmospheric Pressure Chemical Vapor Deposition of TiN from Tetrakis (dimethylamido) Titanium and Ammonia," J. Mater. Res., 11 [4] 989-1001 (1996). (b) Z. Duan and J. G. Verkade, "Synthesis and Characterization of a Novel Azatitanatrane," Inorg. Chem., 34 [8] 431116 (1995). (c) M. E. Gross and T. Siegrist, "Molecular Precursor Chemistry for TiN: Synthesis and Structure of $\left[\mathrm{Ti}\left(\mathrm{NMe}_{2}\right)\left(\mathrm{N}_{3}\right)\left(\mu-\mathrm{NMe}_{2}\right)\right]_{3}\left(\mu_{3}-\mathrm{N}_{3}\right)\left(\mu_{3}-\mathrm{NH}\right)$," Inorg. Chem., 31 [11] 4898-99 (1992).

${ }^{23}$ Y. W. Bae, W. Y. Lee, C. S. Yust, P. J. Blau, and T. M. Besmann, "Synthesis and Friction Behavior of Chemically Vapor Deposited Composite Coatings Containing Discrete TiN and $\mathrm{MoS}_{2}$ Phases," J. Am. Ceram. Soc., 79 [4] 819 24 (1996).

${ }^{24}$ R. M. Laine and A. S. Hirschon, "The Pyrolytic Transformation of Organometallic Compounds into Refractory Metals: Tungsten and Molybdenum Carbides"; pp. 21-31 in Transformation of Organometallic into Common and Exotic Materials: Design and Activation. Edited by R. M. Laine. Martinus Nijhoff, Dordrecht, The Netherlands, 1988.

${ }^{25} \mathrm{G}$. M. Brown and L. Maya, "Ammonolysis Products of the Dialkylamides of Titanium, Zirconium, and Niobium as Precursors to Metal Nitrides," J. Am. Ceram. Soc., 71 [1] 78-82 (1988).

${ }^{26}$ J. Hapke and G. Ziegler, "Synthesis and Pyrolysis of Liquid Organometallic Precursors for Advanced Si-Ti-C-N Composites," Adv. Mater., 7 [4] 380-84 (1995).

${ }^{27}$ (a) Z.-F. Zhang, R. A. Kennish, K. A. Blohowiak, M. L. Hoppe, and R. M. Laine, "Superconducting Fibers From Organometallic Precursors. Part III, HighTemperature Pyrolytic Processing," J. Mater. Res., 8, 1777-90 (1993). (b) Y. Liu, Z.-F. Zhang, B. King, J. Halloran, and R. M. Laine, "Synthesis of Yttrium Aluminum Garnet from Yttrium and Aluminum Isobutyrate Precursors," J. Am. Ceram. Soc., 79 [2] 385-94 (1996).

${ }^{28}$ K. A. Youngdahl, R. M. Laine, R. A. Kennish, T. R. Cronin, and G. A. Balavoine, "New Catalytic Routes to Preceramic Polymers: Ceramic Precursors to Silicon Nitride and Silicon-Carbide Nitride"; pp. 489-95 in Materials Research Society Symposium Proceedings, Vol. 121, Better Ceramics Through Chemistry III. Edited by C. J. Brinker, D. E. Clark, and D. R. Ulrich. Materials Research Society, Pittsburgh, PA, 1988.

${ }^{29}$ L. Maya, D. R. Cole, and E. W. Hagaman, "Carbon-Nitrogen Pyrolyzates: Attempted Preparation of Carbon Nitride," J. Am. Ceram. Soc., 74 [7] 168688 (1991).

${ }^{30} \mathrm{~K}$. Ogata, "Properties of Carbon Nitride Films with Composition Ratio $\mathrm{C} / \mathrm{N}=0.5-3.0$ Prepared by the Ion and Vapor Deposition Method," J. Appl. Phys., 76 [6] 3791-96 (1994).

${ }^{31}$ J. Jagielski, N. Moncoffre, G. Marest, and S. Fayeulle, "Migration of Nitrogen Implanted into Iron Induced by the Presence of a Buried Carbon-Rich Layer," J. Appl. Phys., 76 [9] 5132-35 (1994).

${ }^{32}$ O. Matsumoto, T. Kotaki, H. Shikano, K. Takemura, and S. Tanaka, "Synthesis of Carbon Nitride in Plasma Arc," J. Electrochem. Soc., 141 [2] L16-L18 (1994)

${ }^{33}$ S. P. Withrow, J. M. Williams, S. Prawer, and D. Barbara, "New Carbon Nitride Phase by High-Dose N Ion Implantation in Glassy Carbon," J. Appl. Phys., 78 [5] 3060-65 (1995)

${ }^{34}$ R. P. Subrayan and P. G. Rasmussen, "An Overview of Materials Composed of Carbon and Nitrogen," Trends Polym. Sci. (Cambridge, UK), 3 [5] 16572 (1995).

${ }^{35}$ (a) J. S. Colligon, H. Kheyrandish, L. N. Lesnevsky, A. Naumkin, A. Rogozin, I. I. Shkarban, L. Vasilyev, and V. E. Yurasova, "Composition and Chemical State of Titanium Nitride Films Obtained by Different Methods," Surf. Coat. Technol., 70 [1] 9-17 (1994). (b) C. D. Wagner, W. M. Riggs, L. E. Davis, and J. F. Moulder, Handbook of X-Ray Photoelectron Spectroscopy. Edited by G. E. Muilenberg. Perkin-Elmer, Norwalk, CT, 1979.

${ }^{36} \mathrm{Y}$. Liu and R. M. Laine; unpublished results. 